\author{
UNIVERSIDADE DE SÃO PAULO \\ FACULDADE DE ZOOTECNIA E ENGENHARIA DE ALIMENTOS
}

CAMILA CEREZER SILVA

Ecossistema de inovação no âmbito da rede iberoamericana de incubadoras de empresas inovadoras e parques científicos: o caso da AGROINNCUBA

Pirassununga/SP

2018 
CAMILA CEREZER SILVA

\section{Ecossistema de inovação no âmbito da rede ibero- americana de incubadoras de empresas inovadoras e parques científicos: o caso da AGROINNCUBA}

Dissertação apresentada à Faculdade de Zootecnia e Engenharia de Alimentos da Universidade de São Paulo, como parte dos requisitos para a obtenção do título de Mestre em Ciências do Programa de Gestão e Inovação na Indústria Animal.

Área de Concentração: Gestão e Inovação na Indústria Animal

Orientador: Prof. Dr. Celso da Costa Carrer

\section{Pirassununga/SP \\ 2018}


Ficha catalográfica elaborada pelo

Serviço de Biblioteca e Informação, FZEA/USP, com os dados fornecidos pelo(a) autor(a)

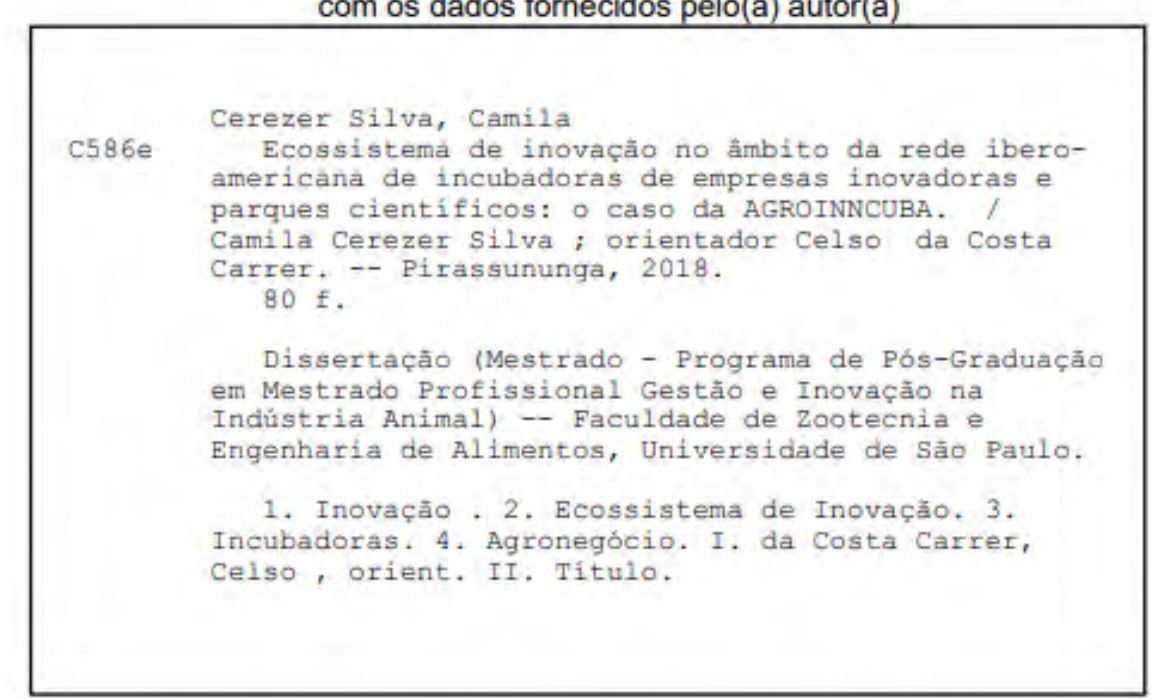

Permitida a cópia total ou parcial degte documento, desde que citada a fonte - $\circ$ autor 


\title{
Ecossistema de inovação no âmbito da rede ibero- americana de incubadoras de empresas inovadoras e parques científicos: o caso da AGROINNCUBA
}

\begin{abstract}
Dissertação apresentada à Faculdade de Zootecnia e Engenharia de Alimentos da Universidade de São Paulo, como parte dos requisitos para obtenção do Título de Mestre em Ciências no Programa de PósGraduação em Gestão e Inovação na Indústria Animal.
\end{abstract}

Data de aprovação: 14/12/2018

Banca Examinadora:

Prof. Dr. Celso da Costa Carrer - Presidente da Banca Examinadora

FZEA/USP - Orientador

Profa. Dra. Maria Angela Fagnani

Prof. Titular UNICAMP

Profa. Dra. Luciene Rose Lemes

Prof. Titular Academia da Força Aérea (AFA)

Prof. Dr. Ricardo Firetti

Prof ${ }^{\mathfrak{a}}$ Titular APTA - Escritório Regional de Presidente Prudente - São Paulo 
Dedico este trabalho primeiramente a Deus, por ser essencial em minha vida, meu guia. Aos meus pais, Genebra e Lázaro, e meu irmão, César, pelo exemplo, dedicação e firmeza com que orientaram minha educação. 


\section{AGRADECIMENTOS}

Aos Professores Doutores Celso da Costa Carrer e Marcelo Machado De Luca de Oliveira Ribeiro, pela convivência e por compartilharem seus conhecimentos, contribuindo desta forma para o meu crescimento científico e intelectual.

Ao Prof. Dr. Celso da Costa Carrer, pela orientação, pelo estímulo incessante e crença inabalável na capacidade de transformação do empreendedorismo.

Ao Programa de Pós-Graduação em Gestão e Inovação na Indústria Animal da FZEA/USP, pela oportunidade de qualificação profissional e de integração entre a vida acadêmica e a corporativa.

À Faculdade de Zootecnia e Engenharia de Alimentos, pela oportunidade de realização do curso de mestrado e, também, de graduação. 
"Seja a mudança que você quer ver no mundo" Mahatma Gandhi 


\section{RESUMO}

SILVA, C. C. Ecossistema de inovação no âmbito da rede ibero-americana de incubadoras de empresas inovadoras e parques científicos: o caso da AGROINNCUBA. 2018. $80 \mathrm{f}$. Dissertação (Mestrado) - Faculdade de Zootecnia e Engenharia de Alimentos, Universidade de São Paulo, Pirassununga, 2018.

O objetivo do presente estudo foi levantar o modelo de formação do ecossistema de inovação que orbita as incubadoras integrantes da rede alvo, AGROINNCUBA, identificando as variáveis que compõem o ecossistema e avaliando a resultante deste processo no desempenho de empresas inovadoras voltadas para o agronegócio. A fim de caracterizar o modelo de formação de cada ecossistema de inovação da rede, a metodologia utilizada foi baseada em pesquisa quantitativa (análise multivariada) com os Coordenadores e empreendedores das incubadoras filiadas à AGROINNCUBA, através de um questionário com respostas abertas e fechadas aplicado online via Google formulários, além de entrevistas com os gestores das incubadoras e parques participantes. Os atores dos ecossistemas de inovação da rede AGROINNCUBA, têm desenvolvido uma cultura direcionada a inovação, dedicando-se a pensar e agir de forma a gerir o conhecimento por meio da tecnologia da informação, da organização do trabalho, da gestão da inovação, gestão de pessoas e de recursos, possibilitando assim ambientes que estimulem a criatividade, a viabilização de talentos, contribuindo para o seu desenvolvimento e fortalecimento. Diante do levantamento realizado para a verificação da existência de um ecossistema de inovação estabelecido ao redor das incubadoras e parques científicos da rede AGROINNCUBA, pode-se afirmar que este conjunto de atores tem contribuído para a geração de novos negócios inovadores, assim, promovendo o desenvolvimento econômico e social.

Palavras-chave: inovação, ecossistema de inovação, incubadoras, agronegócio. 


\begin{abstract}
SILVA, C. C. Innovation ecosystem in the context of the Ibero-American network of incubators of innovative companies and scientific parks: the case of AGROINNCUBA. 2018. 80 f. M.Sc. Dissertation - Faculdade de Zootecnia e Engenharia de Alimentos, Universidade de São Paulo, Pirassununga, 2018.

The objective of the present study was to analyze the formation model of the innovation ecosystem that orbits the incubators of the target network, AGROINNCUBA, identifying the variables that compose the ecosystem and evaluating the resulting process in performance of innovative agribusiness companies. In order to characterize the formation model of each innovation ecosystem, the methodology used was based on quantitative (multivariate analysis) and qualitative (discourse analysis) research with coordinators and entrepreneurs from the incubators affiliated with the AGROINNCUBA, through a questionnaire with open and closed responses applied online via Google forms and interviews with the managers of the participating incubators. The actors of the innovation ecosystems of the AGROINNCUBA network, have developed a culture directed to innovation, dedicating themselves to thinking and acting in order to manage knowledge through information technology, work organization, Innovation management, Management of people and resources, thus enabling environments that stimulate creativity, the feasibility of talents, contributing to their development and strengthening. In view of the survey carried out to verify the existence of an innovation ecosystem established around the incubators and scientific parks of the AGROINNCUBA network, it can be affirmed that this set of actors has contributed to the generation of new Innovative business, thus promoting economic and social development.
\end{abstract}

Keywords: innovation, innovation ecosystem, incubators, agribusiness. 


\section{LISTA DE FIGURAS}

Figura 1 - Evolução do modelo de inovação nas últimas décadas.........................23

Figura 2 - Componentes gerais de um ecossistema de inovação em universidades.

Figura 3 - Rede de interação do Agribusiness ............................................29

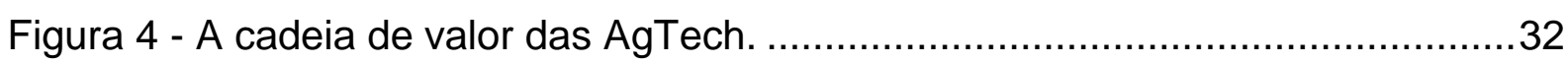

Figura 5 - Principais áreas de atuação das AgTech no Brasil..............................33

Figura 6 - Principais áreas de atuação das AgTech no Brasil.............................34

Figura 7 - Principais mercados atingidos pelas AgTech no Brasil...........................35

Figura 8 - Diagrama dos autovalores para os fatores calculados, considerando-se os 8 indivíduos (incubadoras) e 7 variáveis relacionadas a dados fornecidos pelos Coordenadores das incubadoras da Rede AGROINNCUBA. ................................52 


\section{LISTA DE TABELAS}

Tabela 1 - Resumo de algumas das definições existentes sobre o termo Ecossistema de Inovação e suas variações.

Tabela 2 - Evolução das definições de inovação ao longo do tempo, por diferentes autores.

Tabela 3 - Modelo de Negócios das Startups

Tabela 4 - Resultados de autovalores e \% das variâncias total e acumulada para os 8 indivíduos (incubadoras) e 7 variáveis relacionadas a dados fornecidos pelos Coordenadores das incubadoras da Rede AGROINNCUBA. .52

Tabela 5 - Resultados de coeficientes de correlação para os cinco fatores calculados, considerando-se os 8 indivíduos (incubadoras) e 7 variáveis relacionadas a dados fornecidos pelos Coordenadores das incubadoras da Rede AGROINNCUBA. .53 


\section{LISTA DE SIGLAS}

ACP - Análise de Componentes Principais

ANPROTEC - Associação Nacional de Entidades Promotoras de Empreendimentos Inovadores

CIAT - Centro Internacional de Agricultura Tropical

CIEE - Centro Institucional de Empreendedorismo Corporativo

CNA - Confederação da Agricultura e Pecuária do Brasil

CORPOICA - Corporação de Pesquisa colombiano Agropecuaria

$\mathrm{CP}$ - Componentes Principais

CSIC - Conselho Superior de Pesquisas Científicas

CYTED - Programa Ibero-Americano de Ciência e Tecnologia para o

Desenvolvimento

ESALQ - Escola Superior de Agricultura "Luiz de Queiroz"

FPCUV - Fundació Parc Científic Universitat de València

FZEA - Faculdade de Zootecnia e Engenharia de Alimentos

ICA - Instituto Colombiano Agropecuário

IRTA - Instituto de Agricultura e Alimentação Research

ISA - Instituto Superior de Agronomia

MAPA - Ministério da Agricultura, Pecuária e Abastecimento

OCDE - Organização para a Cooperação Econômica e Desenvolvimento

PCUV - Parque Científico da Universidade de Valência

PIB - Produto Interno Bruto

PRUAB - Parque de Recerca UAB

TI -Tecnologia da Informação

UAB - Universidade Autônoma de Barcelona

UAO - Universidad Autonoma de Occidente

UNLP - Universidade Nacional de La Plata

USP - Universidade de São Paulo

UV - Universidade de Valência 


\section{SUMÁRIO}

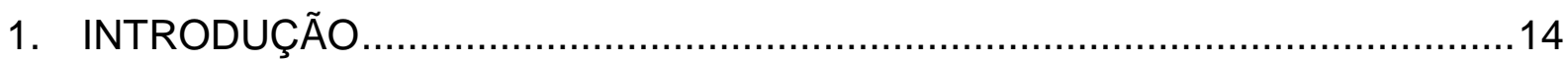

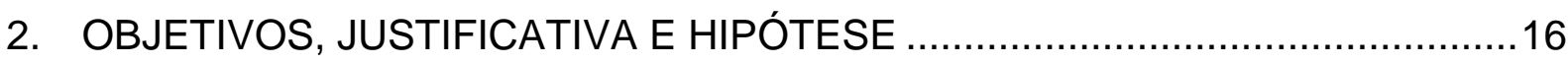

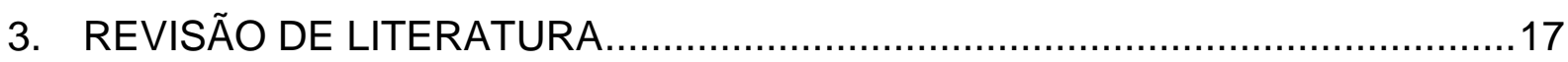

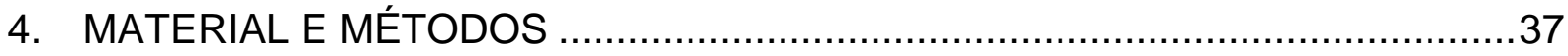

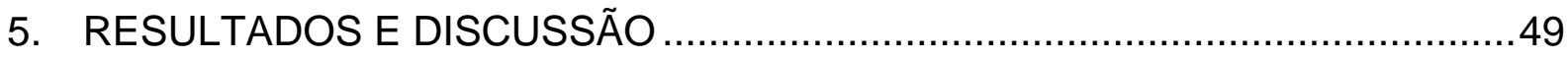

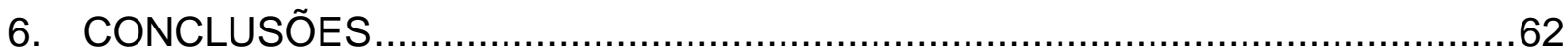

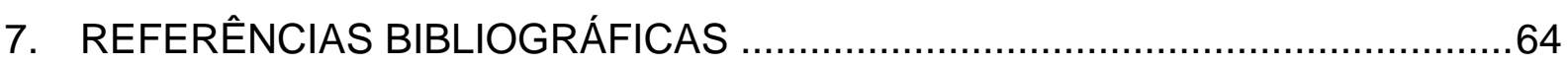

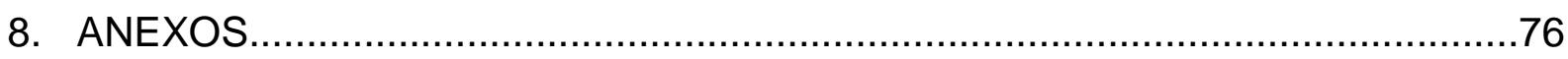

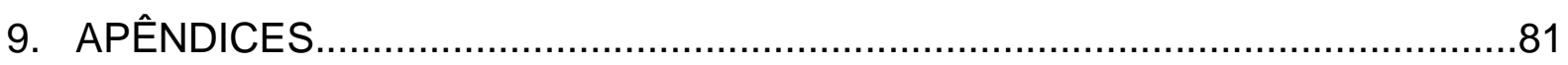




\section{INTRODUÇÃO}

O conceito de Ecossistemas de Inovação tem sido trabalhado como equivalente às áreas de inovação, buscando estabelecer um paralelo ou uma metáfora com os ecossistemas naturais, onde a vida se cria, se adapta e evolui, com intensa interação e sinergia (AUDY, 2017).

O grau de interconectividade é elemento fundamental da analogia, de interdependência que todos os componentes do sistema guardam entre si (MOORE, 1996). Essa interdependência, como numa cadeia trófica, garante a produtividade, a criatividade e estabilidade do ecossistema. O desenvolvimento de uma área de inovação necessita de uma série de fatores para ser bem-sucedido no processo de transformação econômica, social e urbana envolvida (AUDY, 2017).

As atividades de inovação de um negócio possuem dependência da heterogeneidade e da estrutura de suas relações com as fontes de informação, conhecimento, tecnologias, práticas e recursos humanos e financeiros. Cada interação é responsável pela conexão com o negócio inovador e com outros atores do sistema: laboratórios governamentais, universidades, departamentos de políticas, reguladores, competidores, fornecedores e consumidores (OCDE, 1997).

Segundo Feferman (2011), a diferenciação competitiva só se dá pela inovação, o que possibilita entregar novas soluções para as necessidades dos consumidores, bem como para as oportunidades identificadas no mercado. Ainda segundo o autor, a inovação é o processo-chave da competitividade e, em todo negócio, os incentivos a ela podem e devem existir, tanto nos produtos como nos serviços, comunicação, processos e modelos de negócio.

Diversos sistemas e mecanismos vêm sendo mundialmente utilizados para estimular a criação de empresas inovadoras. Na gênese da maioria dos ecossistemas de empreendimentos inovadores ao redor do planeta encontram-se os pólos, parques tecnológicos, incubadoras de empresas, distritos industriais, escolas de empreendedores, centros de inovação, entre outros, cada qual com peculiaridades próprias, assistindo às variadas fases do processo de criação de empresas, desde a geração da ideia, passando pelas etapas de pesquisa, desenvolvimento de protótipo, 
transformação da ideia em processo, produto ou serviço e, finalmente, a produção em escala.

As incubadoras de empresas, sobretudo aquelas de base inovadora, são consideradas por especialistas como o principal mecanismo de estímulo a esse novo paradigma de negócios (RANTIN, 2016). No ambiente negocial dos sistemas agroalimentares, a nova geração de empresas que agrega conhecimento como um dos principais diferenciais para a sua trajetória empresarial é denominada AGTech.

Neste contexto, a AGROINNCUBA - Rede Iberoamericana de Incubadoras de Empresas Agroalimentares - nasceu observando a necessidade de desenvolvimento de novos negócios e do suporte às empresas nascentes no segmento do agronegócio em vários países. A rede é composta de incubadoras de empresas e parques científicos e tecnológicos entre as instituições: Faculdade de Zootecnia e Engenharia de Alimentos da Universidade de São Paulo, Brasil; Parc Científic de la Universitat de València e Universidad Autónoma de Barcelona, Espanha; Universidad Autónoma de Occidente e Universidad Parque Científico e Biotecnológico do Pacífico, Colômbia; Universidad de La Frontera, Chile; Universidad de Técnica Particular de Loja, Equador; Universidad Nacional de La Plata, Argentina e Universidade de Lisboa, Portugal.

Diante da importância que o setor do agronegócio brasileiro apresenta para a sustentação da economia brasileira, já há algumas décadas, buscou-se aprofundar o entendimento de como uma rede internacional que se propõe a reunir Incubadoras e Parques Científicos/Tecnológicos, vocacionados em abrigar este setor de AGTech, faz parte desse Ecossistema de Inovação e opera para atingir o objetivo maior de fomentar o nascimento e crescimento destas empresas e o consequente desenvolvimento deste setor da economia. 


\section{OBJETIVOS, JUSTIFICATIVA E HIPÓTESE}

A rede AGROINNCUBA prevê uma série de iniciativas de órgãos de países Iberoamericanos, a fim de desenvolver estratégias para impulsionar o setor do agronegócio, tais como: promover o intercâmbio de conhecimento entre as empresas incubadas, buscar novos mercados de atuação e apoio dos projetos já desenvolvidos e gerar um manual de boas práticas de gestão tecnológica e empreendedoras para a rede. Dentre elas, destaca-se a importância de avaliar o ecossistema de inovação, visando contribuir para o aumento do nível de interação e consequente fortalecimento da rede internacional estudada.

Para Spinosa e Krama (2014), os ecossistemas de inovação podem ser definidos como ativos de competitividade na economia do conhecimento e caracterizam-se por ter como objetivos: a) promover a cultura da inovação, da competitividade das empresas e das instituições de pesquisa, b) estimular e gerenciar o fluxo de conhecimento e tecnologia entre as universidades, centros de pesquisa e desenvolvimento, empresas e seus mercados, c) facilitar a criação e consolidação de empreendimentos por meio da incubação, além de prover outros fatores agregados com espaço de qualidade e infraestrutura, d) gerar sinergia entre os diversos atores identificando as vocações locais e regionais, buscando viabilidade econômica e tecnológica.

Tendo em vista esta necessidade, o presente estudo tem o propósito de levantar o modelo de formação do ecossistema de inovação que orbita as incubadoras integrantes da rede alvo, AGROINNCUBA, identificando as variáveis que compõem o ecossistema e avaliando a resultante deste processo no desempenho de empresas inovadoras voltadas para o agronegócio.

A hipótese a ser validada pressupõem que: "As Incubadoras de Empresas e Parques Científicos membros da Rede AGROINNCUBA caracterizam-se como um ecossistema de inovação que busca apoiar o desenvolvimento de empresas inovadoras no segmento agroalimentar". 


\section{REVISÃO DE LITERATURA}

\subsection{O Conceito de Ecossistema de Inovação e o contexto no desenvolvimento econômico e social}

Ecossistemas de Inovação têm ganhado relevância em diversas regiões do mundo e em diferentes áreas do conhecimento, reunindo governo, indústria, academia e usuários de forma geográfica ou pelo uso intensivo das tecnologias de informação e comunicação. O ecossistema de inovação pode ser caracterizado como um ambiente propício ao empreendedorismo inovador, que constitui espaços de aprendizagem coletiva, de intercâmbio de conhecimentos e de práticas produtivas de geração de sinergia entre diversos agentes de inovação (SPINOSA e KRAMA, 2014).

Trata-se de uma abordagem aberta e holística, que incentiva a inovação tecnológica em todo o meio através do compartilhamento de informações e colaboração. É um grupo de componentes que trabalham em conjunto para criar um ambiente favorável à inovação e permitir que as tecnologias e inovações sejam competitivas no mercado (THOMPSON et. al. 2012).

O termo "ecossistemas de negócio" foi encontrado pela primeira vez em Zelený et al. (1991) e Moore (1993; 1996) foi quem o impulsionou como uso corrente. O trabalho desenvolvido por Moore (1996), tratando sobre o conceito de "ecossistemas de negócios", é considerado como lapidar para compreensão sobre a dinâmica envolvida em torno da cooperação e concorrência entre as empresas que participam do processo. Segundo o autor, cada ecossistema tem sua própria dinâmica, agregando valor baseado, sobretudo, no conhecimento, para cada um de seus atores envolvidos e para comunidade do entorno do mesmo.

Kolosky, Speroni e Gauthier (2015) realizaram um aprofundado levantamento de literatura que apontou, na época do estudo, a ocorrência de 230 artigos de língua inglesa nas bases de dados científicas Web of Science, Scopus, EBSCO e IEEE, sendo encontrado dentre estes, apenas um único trabalho brasileiro. Concluíram que, a partir de 2010, houve um aumento exponencial no número de trabalhos enfocando esta temática, que trouxe grande diversidade de definições para o entendimento do conceito de um ecossistema de inovação. A resultante final acaba dependendo do contexto em pauta, havendo variações do termo como ecossistema de negócios e, também, ecossistema empreendedor. 


\section{A Tabela 1, a seguir, apresenta autores relevantes e suas respectivas definições do termo Ecossistema no contexto do estudo.}

\section{Tabela 1 - Resumo de algumas das definições existentes sobre o termo Ecossistema de Inovação e suas variações.}

\begin{tabular}{|c|c|}
\hline $\begin{array}{l}\text { Autor(es) e } \\
\text { Data de publicação }\end{array}$ & Definição \\
\hline MOORE (1993) & $\begin{array}{l}\text { "Um ecossistema de negócios [...] atravessa uma variedade de indústrias [...], as } \\
\text { empresas coevoluem capacidades em torno de uma nova inovação: eles trabalham } \\
\text { cooperativamente e competitivamente para apoiar novos produtos, satisfazer as } \\
\text { necessidades dos clientes, e, eventualmente, incorporar a próxima rodada de } \\
\text { inovações. Cada ecossistema de negócios desenvolve-se em quatro estágios } \\
\text { distintos: nascimento, expansão, liderança e auto renovação - ou, se não a auto } \\
\text { renovação, a morte. [...] enquanto o centro pode mudar ao longo do tempo, o papel } \\
\text { do líder é valorizado pelo resto da Comunidade. Tal liderança permite que todos os } \\
\text { membros do ecossistema investirem em um futuro compartilhado no qual eles } \\
\text { antecipam a lucratividade. " (p. } 76)\end{array}$ \\
\hline IANSITI e LEVIEN (2004) & $\begin{array}{l}\text { "[...] o desempenho dessas empresas [...] deriva de algo que é muito maior do que } \\
\text { as próprias empresas: o sucesso de seu respectivo ecossistema de negócios. } \\
\text { Essas redes não ligadas - de fornecedores, distribuidores, empresas terceirizadas, } \\
\text { fabricantes de produtos ou serviços relacionados, provedores de tecnologia e uma } \\
\text { série de outras organizações - afetam e são afetadas pela criação e entrega de } \\
\text { ofertas próprias de uma empresa. " (p. 01) }\end{array}$ \\
\hline ADNER (2006) & $\begin{array}{l}\text { "[...] ecossistemas de inovação — os arranjos colaborativos através dos quais as } \\
\text { empresas combinam suas ofertas individuais em uma solução coerente que atende } \\
\text { às necessidades do consumidor" (p. 02) }\end{array}$ \\
\hline ADNER e KAPOOR (2010) & $\begin{array}{l}\text { "A construção do ecossistema, como uma forma de tornar as interdependências } \\
\text { mais explícitas, [...] centraram-se na compreensão da coordenação entre parceiros } \\
\text { em redes de intercâmbio que se caracterizam pela cooperação e concorrência } \\
\text { simultâneas. " (p. 309) }\end{array}$ \\
\hline ISENBERG (2010) & $\begin{array}{l}\text { "O ecossistema de empreendedorismo consiste em um conjunto de elementos } \\
\text { individuais - como liderança, cultura, mercados de capitais e clientes de mente } \\
\text { aberta - que se combinam de maneiras complexas." p. (41) }\end{array}$ \\
\hline MALECKI (2011) & $\begin{array}{l}\text { "(...) as redes locais ou regionais de empresários, instituições de apoio e fontes de } \\
\text { financiamento (por exemplo, capital de risco) mantêm a energia criativa em regiões } \\
\text { com ecossistemas empresariais " (p. 43) }\end{array}$ \\
\hline ZAHRA e NAMBISAN (2012) & $\begin{array}{l}\text { "Um ecossistema de negócios é um grupo de empresas - e outras entidades, } \\
\text { incluindo indivíduos - que interage e compartilha um conjunto de dependências à } \\
\text { medida que produz os bens, tecnologias e serviços que os clientes precisam (...) e } \\
\text { são muitas vezes moldadas por um pivô central que fornece os incentivos para } \\
\text { outras empresas para coevoluir, alinhar seus objetivos e atividades, e se unir } \\
\text { mutuamente um ao outro " (p. } 220)\end{array}$ \\
\hline KAPOOR e LEE (2013) & $\begin{array}{l}\text { "As empresas estão inseridas em um ecossistema de negócios de atividades } \\
\text { interdependentes realizadas por seus clientes, complementadores e fornecedores. } \\
\text { Essas interdependências sustentam a capacidade das firmas de retornos } \\
\text { adequados de investimentos em novas tecnologias". (p. 276) }\end{array}$ \\
\hline LETEN et al. (2013) & $\begin{array}{l}\text { "os ecossistemas podem ser feitos de diferentes conjuntos de parceiros em } \\
\text { momentos diferentes em que as empresas colaboram e associam seus recursos } \\
\text { em uma base temporária para alcançar objetivos de inovação conjunta, } \\
\text { compartilhando custos e riscos associados. Os ecossistemas de inovação geram } \\
\text { valor para os parceiros reduzindo custos e riscos de desenvolvimento e combinando } \\
\text { conhecimentos complementares, permitindo que os parceiros abortem problemas } \\
\text { de alta complexidade." (p. } 51 \text { ) }\end{array}$ \\
\hline
\end{tabular}

Fonte: Autoria própria, adaptado da literatura citada. 
As diferentes definições do termo tratam, assim como em Spolidoro (2011), "Ecossistema de Empreendedorismo e Inovação" como uma organização em que a premissa básica é contribuir para o processo de desenvolvimento local e regional, reunindo atores cujas competências e funções reforçam um ao outro, promovendo assim a sinergia entre os participantes. O autor ainda salienta que este tipo de ecossistema é um ambiente que deve gerar uma capacidade sustentável de inovação em todos os domínios, construída por atores diversos que geram inovação, em um movimento que se complementa e se reforça (embora possam ser concorrentes), por meio da promoção de condições para criação, atração, instalação e desenvolvimento de empreendimentos inovadores e intensivos em conhecimento.

A analogia entre organismos vivos com o ambiente empresarial é consistente pela afinidade entre suas lógicas de funcionamento. De fato, ambas podem ser referidas como sistemas abertos, ou seja, onde há intercâmbio entre o sistema e o ambiente em que está situado (FLEURY, 1974), provocando mudanças - do ambiente no sistema e do sistema no ambiente.

Segundo Audy (2017), ecossistema de inovação remete ao modelo da Rainforest (Floresta Tropical) denotado por sua exuberância, inconstância, diversidade e sua constante transformação e evolução, esse ambiente exerce grande influência sobre o desenvolvimento de empresas inovadoras e propicia o florescimento da inovação.

Conceitualmente, de um lado, o ecossistema biológico é um conjunto complexo de relações entre os recursos vivos, habitats e moradores de uma certa área, na qual o objetivo funcional é manter um estado de equilíbrio de sustentação. Enquanto que, por outro lado, um ecossistema de inovação modela a dinâmica econômica e não a dinâmica de energia de relações complexas que são formadas entre atores ou entidades. Neste contexto, o objetivo funcional do segundo ecossistema é promover desenvolvimento tecnológico e inovação (JACKSON, 2011). Assim, entende-se que a inovação no ecossistema de negócios é comparável a dinâmica de energia que flui no sistema biológico e descreve o estado de equilíbrio de uma cadeia trófica, justificando o termo sugerido pelos autores já citados.

Remetendo-se ao histórico clássico desta temática, Schumpeter (1934) foi quem deu à inovação um lugar de destaque na teoria do desenvolvimento econômico, focalizando o processo de desenvolvimento econômico nas economias capitalistas 
sob o impacto das inovações tecnológicas. Esse conceito era muito inovador para a época em que foi proposto e contrapõe a ideia do equilíbrio geral da economia. Desde então, acredita-se que a inovação seja a fonte fundamental de geração de riqueza significativa dentro de uma economia desenvolvida.

Ainda segundo Schumpeter (1985), as inovações são responsáveis pela introdução de novos produtos ou significativamente melhorados (bens ou serviços), processos, métodos e estratégias de marketing, que provocam uma ruptura no sistema de equilíbrio perfeitamente competitivo (representado pelo fluxo circular, no qual a vida econômica ocorre de forma semelhante ano após ano); estabelecendo fontes de diferenciação para as empresas e revolucionando as estruturas produtivas no processo de desenvolvimento.

Inovação, de um modo geral e amplo, pode ser caracterizada por levar o conhecimento a ser utilizado em produtos, processos e serviços aptos a serem disponibilizados no mercado (OCDE, 1997). Como se pode observar na Tabela 2, o conceito de inovação tem evoluído ao ser trabalhado por diferentes autores que enfocam aspectos distintos, a partir de suas experiências e visão de mundo complementares.

A inovação, vista como diferencial competitivo, tem sido usada como estratégia e tem se tornado cada vez mais significativa para o progresso e para a evolução socioeconômica dos países, pois coloca em pauta a necessidade da criação de ambientes que estimulem a geração de negócios. Nas décadas mais recentes, governos têm considerado a inovação como fator chave para seu desenvolvimento socioeconômico, através da geração de empregos qualificados para a população e divisas para o país pelo aumento da competitividade industrial. Alguns países têm obtido melhores resultados através do reforço e ampliação de políticas científicas, tecnológicas, e de inovação que realçam a mobilização dos processos de aquisição e o uso de conhecimentos e de capacitações inovadoras como parte integrante e fundamental de suas estratégias de desenvolvimento (OCDE, 2010). 
Tabela 2 - Evolução das definições de inovação ao longo do tempo, por diferentes autores.

\begin{tabular}{|c|c|}
\hline Autor & Conceito \\
\hline Schumpeter (1985) & $\begin{array}{l}\text { A inovação se distingue da invenção, visto que esta é a descoberta da oportunidade } \\
\text { e a primeira é a exploração de uma oportunidade lucrativa. }\end{array}$ \\
\hline Vieira (1995) & $\begin{array}{l}\text { Inovação, é a utilização econômica e social do estado atual do conhecimento } \\
\text { humano. }\end{array}$ \\
\hline Kuczmarski (1996) & $\begin{array}{l}\text { A inovação é um conjunto de ideias contundentes que permitem visualizar além do } \\
\text { presente e criar uma visão futura de negócios. }\end{array}$ \\
\hline Corona $(1997$, p.114) & $\begin{array}{l}\text { Inovação depende tanto do processo anterior, incluindo o desenvolvimento } \\
\text { tecnológico, quanto da posterior criação e extensão do impacto sobre o aparelho } \\
\text { produtivo ou sobre o consumo. }\end{array}$ \\
\hline Drucker (1998) & $\begin{array}{l}\text { Ato de criar um recurso, sendo que a inovação sistemática é a busca deliberada e } \\
\text { organizada de mudanças, através de ampla análise das oportunidades que tais } \\
\text { mudanças podem oferecer para a inovação econômica ou social. }\end{array}$ \\
\hline Porter (1997) & $\begin{array}{l}\text { A inovação pode ocorrer, não somente nas novas tecnologias, mas também em } \\
\text { projetos de novos produtos, novos processos de produção, novos enfoques de } \\
\text { marketing e até mesmo, em uma nova maneira de formular ou organizar-se. }\end{array}$ \\
\hline Souza Neto (1998, p.14) & $\begin{array}{l}\text { Inovação é a ação que conduz à mudança na forma como as coisas são feitas, isto } \\
\text { é, uma mudança em um produto, em um processo ou em um serviço (no mercado). }\end{array}$ \\
\hline $\begin{array}{l}\text { Santana, Hasenclever e Mello (2003, } \\
\text { p.153), citando Dosi (1998) }\end{array}$ & $\begin{array}{l}\text { Essencialmente a inovação diz respeito à busca e a descoberta, experimentação, } \\
\text { desenvolvimento, imitação e adoção de novos produtos, novos processos de } \\
\text { produção e novos arranjos organizacionais. }\end{array}$ \\
\hline Burlamaqui e Proença (2003) & $\begin{array}{l}\text { A inovação (nas empresas) tem sua origem nos rebaixamentos de custos, ganhos } \\
\text { de produtividade e de qualidade e na monopolização temporária de uma } \\
\text { oportunidade de mercado. }\end{array}$ \\
\hline
\end{tabular}

Fonte: Autoria própria, adaptado da literatura citada.

Atualmente, é largamente difundido o conceito de que a inovação, em seu mais amplo espectro, se constitui como a principal ferramenta mercadológica de competição (OCDE, 1997). Para Schumpeter (1961), a inovação que os indivíduos ou as empresas efetuam das mais diversas formas é a principal fonte de concorrência. É por meio dela que se pode obter vantagens em relação aos seus rivais. Dessa forma, a competitividade via preços perde destaque, pois:

"Na realidade capitalista e não na descrição contida nos manuais, o que conta não é esse tipo de concorrência, mas a concorrência de novas mercadorias, novas técnicas, novas fontes de suprimento, novo tipo de organização (a unidade de controle na maior escala possível, por exemplo) - a concorrência que determina uma superioridade decisiva no custo ou na qualidade e que fere não a margem de lucros e a produção de firmas existentes, mas seus alicerces e a própria existência" (SCHUMPETER, 1961). 
Diante desta realidade, é possível afirmar que custo e qualidade são aspectos que podem ser facilmente copiados e replicados, sendo assim, cabe a inovação promover geração de valor.

\begin{abstract}
"As inovações são importantes não somente para aumentar a riqueza das nações no estrito sentido de aumentar a prosperidade, mas também no sentido mais fundamental de permitir às pessoas fazerem coisas que nunca haviam sido feitas anteriormente. Elas possibilitam modificar toda a qualidade de vida para melhor ou para pior. E podem envolver não apenas maiores quantidades dos mesmos bens, como padrões de bens e serviços que nunca existiram previamente, exceto em nossa imaginação" (FREEMAN e SOETE, 2008).
\end{abstract}

As organizações que buscam alto crescimento, tem dado pouca atenção em atingir seus concorrentes, elas procuram fazer com que a concorrência se torne irrelevante através da lógica estratégica da inovação de valor (KIM e MAUBORGNE, 1997). A inovação que agrega valor é uma nova maneira de raciocinar sobre a execução da estratégia, que resulta na criação de um novo espaço de mercado e no rompimento com a concorrência (KIM e MAUBOURGNE, 2005).

A inovação que agrega valor ao final aos produtos e serviços atribui a mesma ênfase ao valor em si e ao processo de inovação. Valor sem inovação tende a concentrar-se na criação de valor em escala experimental, algo que aumenta o valor, mas não é suficiente para sobressair-se no mercado. Inovação sem valor tende a ser movida por tecnologia, promovendo pioneirismo ou futurismos que talvez se situem além do que os compradores estejam dispostos a aceitar e a comprar (KIM e MAUBOURGNE, 2005).

Rothwell (1995) avalia que nas últimas décadas a percepção do modelo de inovação dominante e as práticas inovadoras têm passado por mudanças consideráveis, como pode ser verificado na Figura 1. 
Figura 1 - Evolução do modelo de inovação nas últimas décadas.
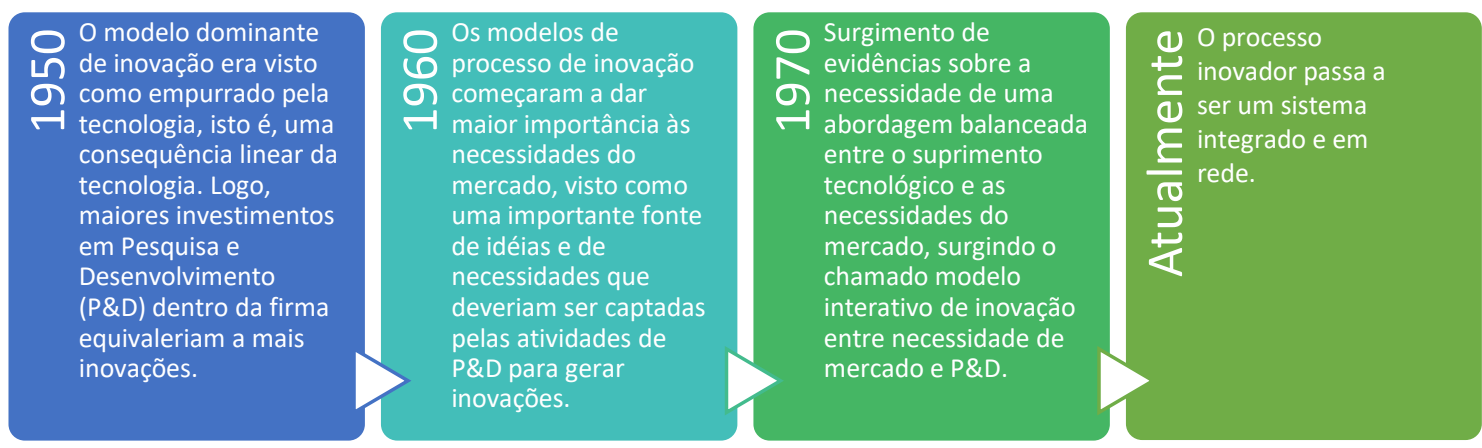

Fonte: adaptado de Rothwell (1995).

Mais recentemente, a inovação foi assumida como uma ação conjunta e cooperada de diversos atores internos e externos à organização, como empresas, fornecedores, clientes, além de outras instituições de caráter público ou privado. Dessa maneira, segundo evidências apresentadas por Rothwell (1995), o atual processo de inovação é representado pela interação e pelas ações conjuntas entre empresas em uma ampla rede de cooperação. Tal fato foi corroborado pelo trabalho de Ahuja (2000) ao demonstrar que as relações diretas entre os atores em uma rede afetam positivamente o resultado da inovação por fornecer três benefícios substantivos: conhecimento compartilhado, complementaridade de ações e escala ampliada dos negócios agregados.

Segundo Bellaver (2005), as empresas devem levar em consideração que operarem no mercado sozinhas, sobretudo em um ambiente competitivo e inovador, é trabalhar na contramão das alianças estratégicas. Para o autor, é fundamental garantir e permitir que os ganhos e avanços tecnológicos sejam compartilhados entre todos os parceiros do processo. Isto faz com que todos ganhem vantagens competitivas com melhoria na rotina tradicional da inovação.

De uma maneira mais ampla, um ecossistema de inovação pode ser definido como uma rede de organizações interconectadas, ligadas a uma empresa focal ou plataforma tecnológica, que incorpora tanto produtores e usuários, criando e apropriando novos valores através da inovação (AUTIO e THOMAS, 2013).

Diante deste cenário, os ecossistemas de inovação são elementos cada vez mais essenciais para o desenvolvimento do mercado globalizado, potencializando a inserção da economia local a um nível nacional (SCHLEMM, 2014), pois auxilia as 
empresas a aumentar sua competitividade e capacidade de oferecer estímulos, soluções e desenvolvimento aos mercados nos quais estão inseridos, estimulando a interação entre os diversos atores da sociedade em prol do desenvolvimento econômico e social (CATHARINO; DAMIAO; ZOUAIN, 2006).

\subsection{Atores do Ecossistema de Inovação: incubadoras e universidades}

Para que ocorra o desenvolvimento de atividade inovadora, de forma que este processo alcance uma escala significativa para contribuir com desenvolvimento econômico e social de uma sociedade, é necessário que os diversos atores estejam envolvidos de maneira organizada e sistêmica na construção de um ecossistema com as características anteriormente discutidas (SCHLEMM, 2014).

O passado recente demonstrou que os ecossistemas de inovação geradores de negócios inovadores são originados, normalmente, da relação cinética de ambientes que produzem ciência e tecnologia, tais como universidades institutos de pesquisa que mantêm relações de efetiva cooperação com o setor produtivo e que desempenham um papel de destaque no desenvolvimento local regional. Estas ligações têm implementado iniciativas para proteger, transferir e comercializar os resultados de suas pesquisas e contribuído para formação de empresas de base tecnológica (KOLOSKY; SPERONI e GAUTHIER, 2015).

Segundo Etzkowitz (2009), a inovação tem como bases principais os seguintes atores envolvidos:

- a universidade, como gerador e difusão do conhecimento;

- a empresa, que fará adaptação das renovações para produção em grande escala;

- o governo, que é o formulador de políticas e, principalmente, financiador e regulador deste ambiente.

Ainda, de acordo com o autor, é preciso romper paradigmas da sociedade meramente industrial, onde é necessário que a sociedade se ampare de outras fontes 
de conhecimento contemplando a interação entre governo, universidades e empresa, tratando da inovação como principal foco desta interação. As interações não podem apresentar um sentido linear e sim multidirecional, de tal forma que inovação esteja presente em todo sistema.

O conceito de ecossistema é utilizado na gestão e no discurso econômico, por ser capaz de descrever grupos de atores heterogêneos que trabalham em cooperação e interdependência (Figura 2). Um ecossistema de inovação na universidade deve ser entendido como um vasto conjunto de componentes, internos e externos a ela, que servem como uma ampla e distribuída infraestrutura de suporte à criação de novos negócios. Os componentes (ou atores) do ecossistema de inovação na universidade são as pessoas, empresas, organizações e processos relevantes para a criação de novos negócios e que estão distribuídos através dos ambientes interno e externo da universidade (LEMOS, 2009).

Figura 2 - Componentes gerais de um ecossistema de inovação em universidades.
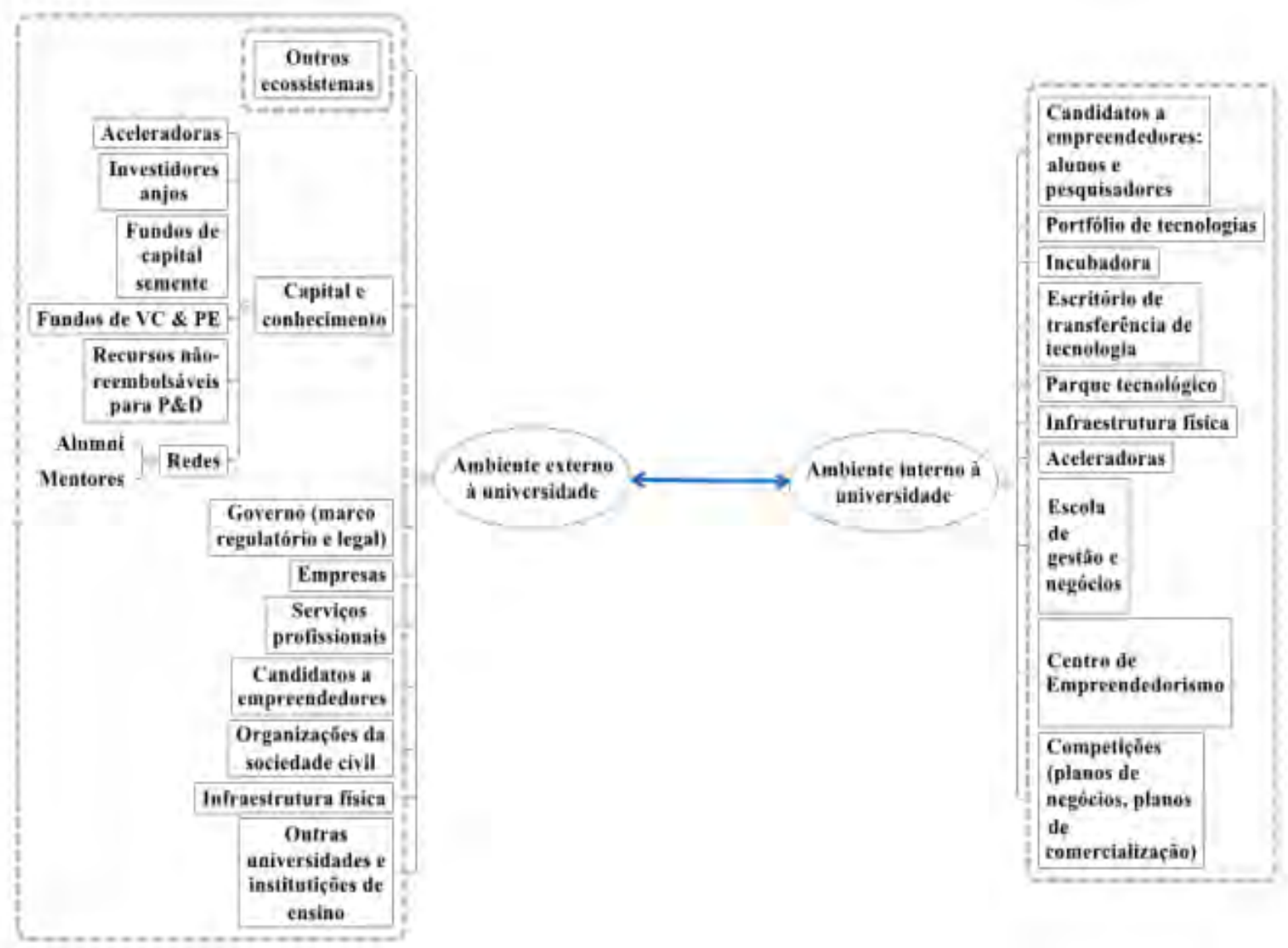

Fonte: Lemos (2009) 
Neste cenário, as incubadoras promovem oportunidades para o desenvolvimento tecnológico do processo produtivo e oferecem aos novos empreendedores, além de espaço físico e serviços de escritório, o apoio administrativo, aconselhamento e consultoria gerencial e de marketing (ZEDTWITZ, 2003).

Por sua vez, a Associação Nacional de Entidades Promotoras de Empreendimentos Inovadores (ANPROTEC, 1999) relaciona a criação de incubadoras como o estímulo à cooperação entre universidades e a sociedade, com a otimização do potencial regional no desenvolvimento econômico, social, tecnológico e, principalmente, com o incentivo ao empreendedorismo.

De acordo com Carrer (2010), a instituição/participação de Parques Tecnológicos e Incubadoras de Empresas, no âmbito ou no entorno das Universidades, precisaria ser uma estratégia prioritária, pois permite que estas se integrem no esforço multidirecional de busca de prosperidade sustentável local e nacional, envolvendo-se diretamente nos processos de inovação, tecnológica ou não.

Segundo Batista (2004), estudos indicam que o desenvolvimento de novas empresas tem uma forte relação com a área da educação. As universidades, sendo importantes geradoras de conhecimento e inovação, podem influenciar nas mudanças das diretrizes do setor coorporativo atual, uma vez que os futuros profissionais, pesquisadores e pensadores que atuam no cenário econômico originaram-se delas.

Atualmente, as universidades são reconhecidas como atores centrais na economia fundamentada no conhecimento, dado que, além de pesquisa e ensino, assumem o papel de empreendedoras e passam a atuar de forma ativa no desenvolvimento econômico regional, mediante a criação de conhecimento científico e tecnológico aplicado e, consequentemente, inovação (ETZKOWITZ et al., 2000).

Hoje consideradas importantes agentes de desenvolvimento local, as universidades têm movido esforços para fornecer suporte aos futuros empreendedores originados em seus laboratórios. A proximidade e a interação entre empresa e universidade possibilitam que se propicie um círculo virtuoso da economia, baseado na geração de conhecimento (científico e, sobretudo, tecnológico) associado a políticas de estímulo à geração de novos negócios (com diferencial competitivo), 
que por sua vez geram resultados, tais como a ocupação no mundo do trabalho, renda e poder de consumo para a população alvo (CARRER, 2010).

De um lado, para potencializar esse papel é importante que a inovação, em sentido amplo, não se limite a um ou a poucos segmentos da instituição, mas a permeie. Mais além de um planejamento para inovação, a universidade contemporânea se beneficiará de um planejamento pela inovação (PLONSKI e CARRER, 2009).

Por outro lado, ainda de acordo com os mesmos autores, as exigências do mercado e do mundo do trabalho requerem uma postura proativa de seus agentes, caracterizada pela busca permanente de oportunidades. É papel da universidade do futuro promover esse capital intelectual de forma abundante e capacitada. É na universidade que se forma a maioria absoluta dos múltiplos atores do complexo processo de inovação tecnológica: empreendedores e gestores, pesquisadores e profissionais técnicos, formuladores e implementadores de políticas públicas, financistas e investidores, operadores do direito e dirigentes de organizações nãogovernamentais, profissionais da imprensa e criadores culturais.

A instituição, além da geração de conhecimento comercializável e de cientistas qualificados, produz outros mecanismos de transferência de conhecimento, como a geração e atração de talentos para a economia local, e a colaboração com a indústria local, fornecendo apoio técnico formal e informal (BRAMWELL e WOLFE, 2008). De acordo com Etzkowitz e Leydesdorff (1997):

"Canalizar fluxos de conhecimento em novas fontes de inovação
tecnológica tem se tornado uma tarefa acadêmica, mudando a
estrutura e a função da universidade. A realização dos benefícios
desta potencial fonte ocorre por meio das inovações organizacionais
tais como escritórios de transferência de tecnologia, instalações de
incubadora e centros de pesquisa com participação industrial. A
mudança na ênfase da concentração na produção e disseminação de
conhecimento para a transferência de tecnologia e a formação de
empresas coloca a universidade em um novo alinhamento com o setor
produtivo".

Carrer et al. (2010) apontam ainda que o capital intelectual não surge sem esforço a partir de um laboratório de pesquisa. É resultado de interação entre pessoas. Com visão global e ação local. É produto da interação entre pesquisadores e professores, alunos capacitados empresas e governo trabalhando juntos em pesquisa de ponta, 
formulando e respondendo questões e atendendo demandas da sociedade por melhores padrões de qualidade de vida. Este contexto requer ambientes de inovação propícios a essas interações globalmente conectados e autossustentáveis

Sendo assim, é a dinâmica das interações entre os atores em um sistema de inovação que permitem a superação de desafios, incrementando a colaboração entre as redes de ciência e tecnologia, incluindo o suporte governamental em áreas estratégicas, promovendo a integração entre os atores da inovação e aumentando a transferência e a aplicação do conhecimento, investimento em pesquisa e desenvolvimento.

As relações entre ciência, tecnologia, inovação e desenvolvimento são interativas, simultâneas e complexas, tendo as pessoas como principal força propulsora de um ciclo virtuoso, a pesquisa como base, a inovação como vetor e o desenvolvimento como consequência (AUDY, 2017).

Como pôde-se observar neste resumido levantamento bibliográfico sobre o tema, diferentes contextos geram diferentes naturezas na tipologia e dinâmica dos ecossistemas de inovação. Muito provavelmente, o contexto histórico combinado com o arranjo institucional, social e econômico do território que dá origem a um ecossistema de inovação, devem se constituir como variáveis fundantes na resultante negocial que conforma a relação cinética final.

Não foram encontrados na literatura, estudos de caso que tenham analisado a estruturação de uma Rede Temática Internacional de Incubadoras e Parques Científicos e Tecnológicos. Mais importante do que sugerir uma dinâmica própria para o ecossistema temático (ligado ao agronegócio, no caso da referida pesquisa), é a possibilidade de explorar uma situação real em que poderá ser diagnosticada as diferentes razões, variáveis próprias e resultantes do fomento de empresas inovadoras na amostra ocasionada pela rede AGROINNCUBA, justificando essa pesquisa. 


\subsection{Inovação no Agronegócio}

O conceito de agronegócio, termo em inglês agribusiness, formulado pelos pesquisadores John Davis e Ray Goldberg na Universidade de Harvard, no final da década de 1950, surge como uma resposta aos desafios ligados à administração das fazendas. Enquanto que de um lado, havia uma capacidade de produção crescente na produção de excedentes, diante dos lançamentos de insumos, máquinas e implementos. De outro, esse processo exigia serviços de comercialização, armazenagem, processamento e transporte, dentre outros, para levar a produção até os centros consumidores (AGROANALYSIS, 2017).

Segundo a PwC Agribusiness Research \& Knowledge Center (2012), o agronegócio não só envolve a produção agropecuária, mas também é constituído por uma rede de elementos que direcionam a sua produção, como mostra a Figura 3.

Figura 3 - Rede de interação do Agribusiness

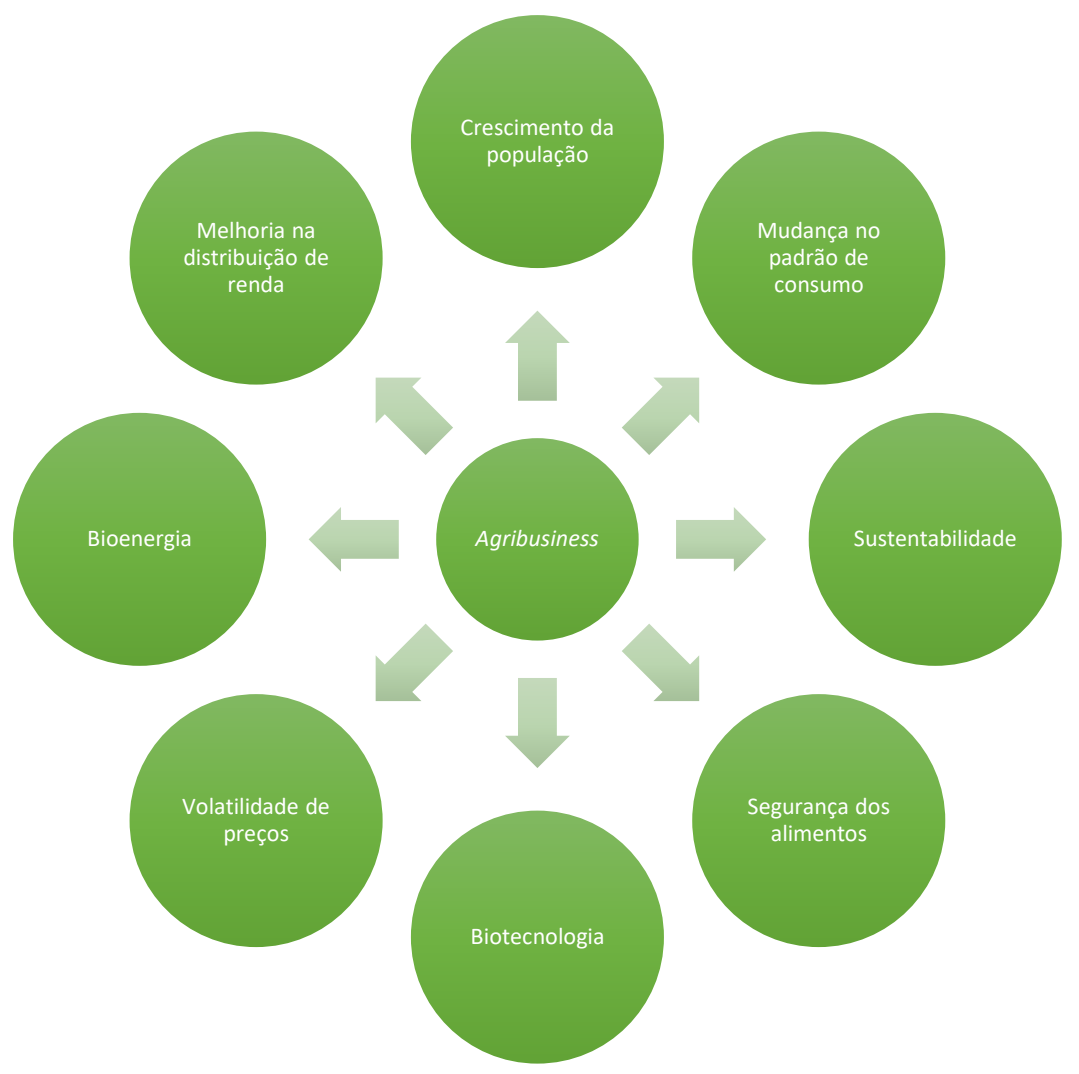

Fonte: Adaptado de PwC Agribusiness Research \& Knowledge Center (2012) 
O conceito tem implicações profundas na organização econômica das nações, particularmente no país, pois o agronegócio é uma das mais importantes fontes geradoras de riqueza do Brasil. A relevância desse complexo para a economia nacional pode ser medida por indicadores como o Produto Interno Bruto (PIB), em que no ano de 2017, a agricultura e o agronegócio contribuíram com $23,5 \%$, sendo esta a maior participação em 13 anos, de acordo com dados da Confederação da Agricultura e Pecuária do Brasil (CNA, 2017).

Ainda, segundo o Ministério da Agricultura, Pecuária e Abastecimento (MAPA), em março de 2018 as exportações brasileiras do Agronegócio somaram US $\$ 9,08$ bilhões, representando um crescimento de $4,1 \%$ em relação ao mesmo período do ano anterior, no qual as vendas totalizaram US $\$ 8,73$ bilhões. Enquanto que, as importações tiveram um registro de -6,9\% comparada ao mesmo mês em 2017.

Contudo, a visão integrada da cadeia produtiva ainda é um constante desafio para o Brasil. Ao mesmo tempo que o Agronegócio representa boa parte das riquezas do país e tem um papel importante no desenvolvimento socioeconômico da nação, o setor é dependente de pesquisas que resultem novos serviços, processos e produtos que ampliem sua eficiência e competitividade.

"A cadeia produtiva é o conjunto de componentes interativos, incluindo os sistemas produtivos, fornecedores de insumos e serviços, industriais de processamento e transformação, agentes de distribuição e comercialização, além de consumidores finais. Objetiva suprir o consumidor final de determinados produtos ou subprodutos" (CASTRO, 2001).

De acordo com Batalha (2012), um elo da cadeia pode ser visto como uma sucessão de operações envolvendo as áreas técnicas, logísticas e comerciais que determinam a passagem da matéria-prima em sucessivas etapas de transformação até chegar às mãos do consumidor na forma de produto acabado. São raras as empresas que conseguem produzir todas as etapas de determinado produto, sendo que processos e/ou produtos inovadores em um elo podem beneficiar a cadeia como um todo.

A ciência e a inovação são as responsáveis pela transformação de nosso país em uma potência no agronegócio, para tanto é necessário aprimorar o processo 
produtivo, buscar sustentabilidade e resolver conflitos entre a produção agropecuária e questões sociais e ambientais.

"Para se garantir a sustentabilidade futura da agricultura, frente às mudanças climáticas e à intensificação de estresses bióticos e abióticos previstos para as próximas décadas, serão necessários substanciais avanços em diversos campos do conhecimento científico e tecnológico. O aumento da demanda por alimentos, fibras e bioenergia exigirá sofisticação tecnológica que racionalize o uso dos insumos ambientais, isto é, os recursos naturais (água, solo, biodiversidade, etc.) e dos serviços ambientais (reciclagem de resíduos, suprimento de água, qualidade da atmosfera, etc.), necessários à produção agropecuária e florestal" (AGROPENSA, 2014).

As empresas mobilizam-se na apresentação de startups com soluções para aumentar a eficiência produtiva do setor. Segundo Gitahy (2010), existem muitas definições em torno desse termo e novo modelo de negócio, sendo o mais usual, segundo ele, o que contempla um grupo de pessoas a procura de um modelo de negócios repetível e escalável (Tabela 3), trabalhando em condições de extrema incerteza.

Tabela 3 - Modelo de Negócios das Startups.

Modelo de Negócios Repetível

Significa que é possível comercializar o mesmo produto ou serviço numa escala potencialmente ilimitada sem necessidade de grandes adaptações a cada cliente ou a cada mercado.

\section{Modelo de Negócios Escalável}

Significa que o negócio pode crescer cada vez mais sem necessidade de alterar o modelo de negócios; este crescimento ocorre essencialmente no lado da receita, sem que os custos cresçam proporcionalmente o que corresponde a um crescimento da margem cada vez maior.

Fonte: Adaptado de NUNES, 2008.

As startups do agronegócio, denominadas AGTech, promovem a geração de valor ambiental, social e econômico, apresentando tecnologias inovadoras no setor agroindustrial que comprovadamente melhoram a prática de sustentabilidade, aumentando a produtividade, melhorando a eficiência e o uso de recursos e reduzindo o impacto ambiental. 
As AGTech têm enorme potencial de inovação na cadeia, que é evidenciado por Dutia (2014) através do diagrama de cadeia de valor da AGTech que rastreia entradas para seus produtos finais apresentado na Figura 4. Segundo o mesmo autor, esta cadeia de valor contém sete etapas intermediárias: entradas físicas, entradas de informações, plantação de plantas, criação de animais, processamento de base biológica, processamento de alimentos e logística. Esta cadeia de valor pode produzir três produtos finais: combustível fóssil substitutos (como o biocombustível), alimentos à base de plantas e alimentos à base de animais. Cada um dos passos na cadeia de suprimentos tem ineficiências e impactos ambientais que podem ser melhoradas. Assim, cada etapa na cadeia de valor tem potencial para inovação.

Figura 4 - A cadeia de valor das AgTech.

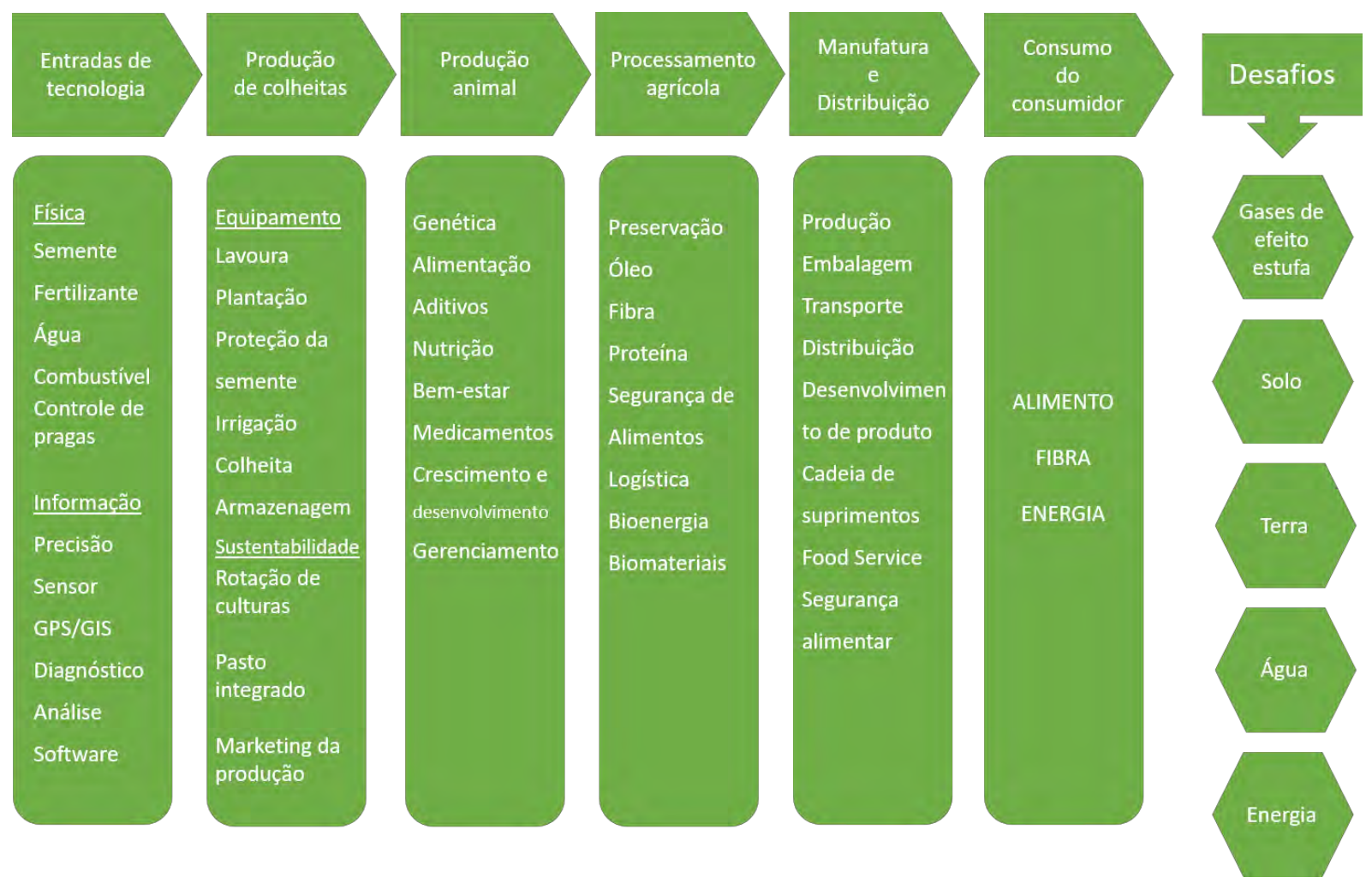

Fonte: Adaptado de DUTIA, 2014.

Vale ressaltar ainda que as inovações nas AGTech não precisam se limitar a apenas uma etapa da cadeia de valor, pois os avanços mais disruptivos da AGTech podem surgir da combinação inovações em múltiplas áreas. Um exemplo desta combinação é a utilização de "sistemas agrícolas integrados", que envolvem e 
integram diversas áreas de conhecimento, tais como: genética, entradas físicas, sensoriamento de Tecnologia de Informação (TI) e maquinário inteligente. Através dos avanços em software e testes ambientais, os agricultores são capazes de criar prescrições de campo para sementes, fertilizantes e controles de pragas. O maquinário inteligente então realiza tratamento prescrito, enquanto coleta dados adicionais que fornece feedback ao agricultor. Esses dados também são úteis para as fazendas e as empresas de insumos no desenvolvimento de produtos personalizados para os agricultores. A ideia de combinar avanços em engenharia genética, tecnologia da informação e maquinário inteligente provavelmente será buscado por muitas empresas estabelecidas e startups, devido ao vasto potencial de investimento e inovações produtos nestas três áreas.

As AGTech no Brasil, apesar de recentes, têm conquistado um espaço significativo no mercado, visando o crescimento do respectivo setor. Ainda, têm buscado tecnologias que permitam uma melhor gestão e que se adaptam rapidamente às mudanças externas além de se manterem competitivas em suas atuações. A fim de avaliar esta movimentação, o $1^{\circ}$ Censo AGTech Startups Brasil, iniciativa da Escola Superior de Agricultura "Luiz de Queiroz" da Universidade de São Paulo (ESALQ/USP), em parceria com o AGTech Garage, realizou o mapeamento do setor de tecnologia do agronegócio brasileiro a partir de um questionário online disponível durante 4 meses, que contou com a participação de 75 startups AGTech.

Figura 5 - Principais áreas de atuação das AgTech no Brasil. 


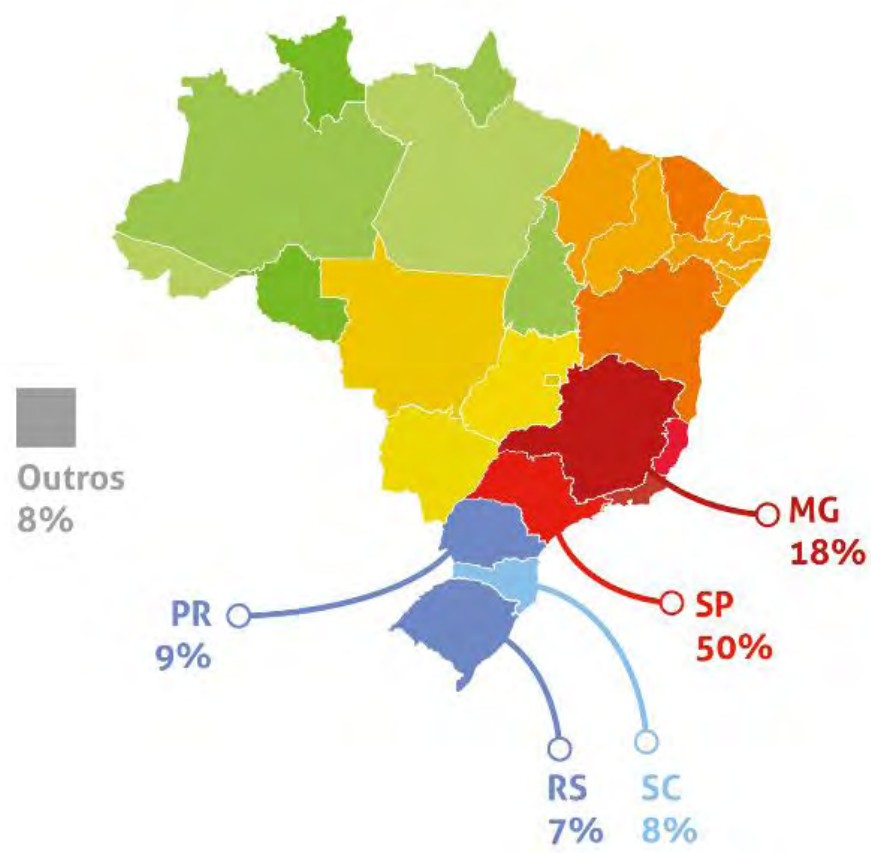

Fonte: AGTech Garage e ESALQ/USP, 2016.

Figura 6 - Principais áreas de atuação das AgTech no Brasil.

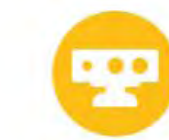

$25 \%$

Equipamentos Inteligentes (IoT) \& Hardware

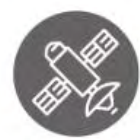

$24 \%$

Agricultura

de Precisão

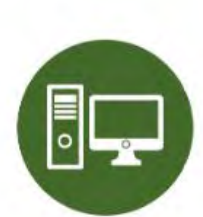

$50 \%$

Softwares para gestão

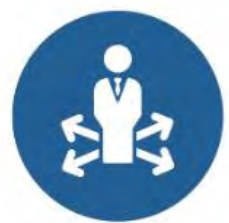

$56 \%$

Tecnologias de

suporte à decisão

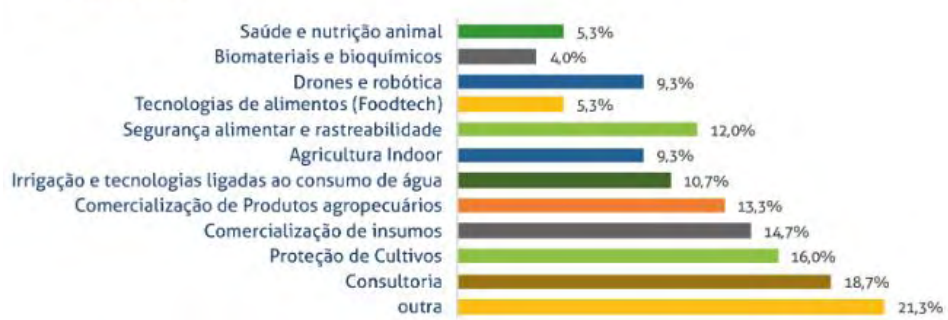

Fonte: AGTech Garage e ESALQ/USP, 2016. 
Figura 7 - Principais mercados atingidos pelas AgTech no Brasil.

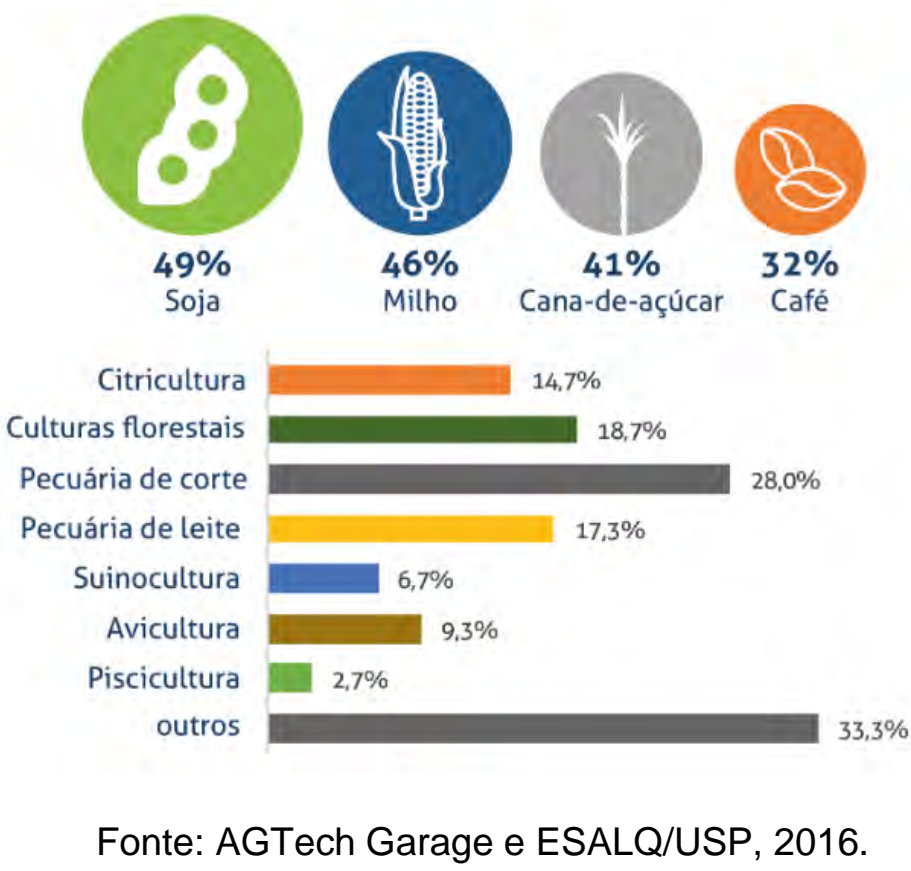


Diante deste cenário, é possível afirmar que existe um processo de modernização no segmento, gradativo e crescente nas últimas décadas, determinando forte dinamismo ao agronegócio brasileiro, cuja evolução deve contar, principalmente, com a contribuição das empresas inovadoras baseadas em conhecimento, as AGTech.

Novas alternativas vão sendo buscadas no mercado uma solução para a viabilização da questão básica de renda negocial do segmento agropecuário e as empresas que conformam o setor. Desse modo, existe claramente toda uma conjuntura internacional globalizada que pressiona o segmento agroalimentar para a consolidação de um novo modelo produtivo e que promova menor impacto do ponto de vista de danos ao ambiente e que seja atrelado a um novo modelo de consumo da população, o qual passa a priorizar aspectos qualitativos. 


\section{MATERIAL E MÉTODOS}

A fim caracterizar o modelo de formação de cada ecossistema de inovação, a metodologia utilizada foi baseada em pesquisa quantitativa (análise multivariada) e qualitativa (análise de discurso) com coordenadores das incubadoras filiadas à AGROINNCUBA, através de um questionário com respostas abertas e fechadas (APÊNDICES 1 e 2) aplicado online via Google formulários e entrevistas com os gestores das incubadoras participantes.

Questionário é um instrumento de coleta de dados, constituído por uma série ordenada de perguntas, que devem ser respondidas por escrito e sem a presença do entrevistador (MARCONI; LAKATOS, 2003). Tal instrumento foi utilizado, não só na pesquisa quantitativa, mas também para identificar os pontos relevantes a serem levantados e analisados na entrevista.

Enquanto que, a entrevista é considerada uma modalidade de interação entre duas ou mais pessoas. Trata-se de uma conversação dirigida a um propósito definido que não é a satisfação da conversação em si, pois esta última é mantida pelo próprio prazer de estabelecer contato sem ter o objetivo final de trocar informações, ou seja, diminuir as incertezas acerca do que o interlocutor diz (HAGUETE, 2001; LODI, 1991).

\subsection{Contextualização do objeto de estudo: a Rede AGROINNCUBA}

Segundo Yin (2005), a escolha dos objetos de estudo deve obedecer a critérios de proximidade com o autor da pesquisa, caso contrário, corre-se o risco de inviabilizála financeiramente ou em termos de validabilidade.

O objeto de estudo, a Rede AGROINNCUBA - Rede Ibero-americana de incubadoras de empresas agroalimentares - foi criada em 2017 com o apoio do Programa Ibero-Americano de Ciência e Tecnologia para o Desenvolvimento $(\text { CYTED })^{1}$, sob a coordenação do Parque Científico da Universidade de Valência

\footnotetext{
1 CYTED é o Programa Ibero-Americano de Ciência e Tecnologia para o Desenvolvimento, criado pelos governos dos países ibero-americanos para promover a cooperação em ciência, tecnologia e inovação para o desenvolvimento harmonioso dos países ibero-americanos. O CYTED alcança os seus objetivos através de diferentes instrumentos de financiamento que mobilizam empresários, investigadores e especialistas ibero-americanos, capacitando-os e permitindo-lhes formar em conjunto projetos investigação, desenvolvimento e inovação. Desta forma, os países que fazem parte do programa CYTED podem manter-se a par dos últimos avanços e desenvolvimentos científicos e tecnológicos. Desde a sua criação em 1984, mais de 28 mil empresários, investigadores e especialistas ibero-americanos participaram do Programa em áreas prioritárias
} 
(PCUV)/Espanha. Em um primeiro encontro ocorrido em maio de 2017, na cidade de Santos/Brasil, representantes de 7 países da América Latina e Europa se reuniram para estreitar o relacionamento entre incubadoras internacionais e desenvolver um plano de ação para a rede nomeada AGROINNCUBA.

O objetivo principal da reunião foi a apresentação e aproximação de todos os membros e, também, o planejamento das ações da rede. A movimentação ocorreu com o propósito de promover o intercâmbio de estratégias para o desenvolvimento da área agroindustrial, alavancagem do potencial de empreender das empresas já incubadas nos respectivos ecossistemas de inovação e potenciais empreendedores interessados em áreas de inovação e tecnologia.

O segundo encontro da AGROINNCUBA foi realizado no mês de maio de 2018, com sede no Parque Científico da Universidade de Valência, Espanha, onde os membros apresentaram os resultados das atividades realizadas em 2017 e programaram suas atividades conjuntas para 2018 junto a rede.

A AGROINNCUBA tem, como objetivo geral, melhorar os níveis de desenvolvimento da inovação e da tecnologia do setor agroalimentar iberoamericano, como mecanismo de criação de emprego, riqueza e bem-estar econômico nas regiões participantes e reforçando especificamente a capacidade das entidades sociais para a prestação de serviços de apoio de alto valor acrescentado para as suas empresas incubadas.

Diante deste cenário, é possível afirmar que a seleção dos atores desta pesquisa seguiu o critério de acessibilidade e direcionamento focado aos colaboradores e beneficiários que trabalham nas instituições que compõe essa rede de incubadoras, facilitando o acesso às informações, opiniões, perspectivas e sugestões, de quem está diretamente ligado ao processo a ser estudado.

Serão descritos, na sequência, todos as instituições que conformam a Rede AGROINNCUBA.

de conhecimento. Os resultados do Programa incluem a criação de projetos estratégicos de P\&D, nos quais participam empresas e especialistas, que a partir da plataforma de cooperação CYTED têm acesso a importantes fundos internacionais. Visualizado em http://www.cyted.org/pt-pt/content/cyted, em 12/11/2018. 


\subsubsection{Faculdade de Zootecnia e Engenharia de Alimentos da Universidade de São Paulo FZEA/USP - Brasil}

A UNICETEC é a incubadora de empresas de Pirassununga que nasceu, em 2009, da iniciativa da Faculdade de Zootecnia e Engenharia de Alimentos (FZEA) da Universidade de São Paulo (USP) e tem como objetivo proporcionar um espaço físico, apoio logístico e aconselhamento de pessoal especializado para o desenvolvimento tecnológico de futuros empreendimentos e projetos de negócios que geram spin-offs e startups na USP.

A base principal consiste no laboratório didático chamado Centro de Inovação, Empreendedorismo e Extensão Universitária Campus USP Pirassununga (UNICETEX), que é uma iniciativa do Grupo de professores na área de Ciências Sociais da FZEA/USP e é constituído como laboratório de iniciativa empreendedora e gestão empresarial.

O UNICETEX reúne workshops e treinamentos, sendo o ponto de encontro para oferecer processos de treinamento, capacitação de recursos humanos e desenvolvimento de perfis empreendedores para apoiar a inovação e a gestão.

A UNICETec possui uma área de aproximadamente 2.100 metros quadrados e uma infraestrutura de serviços de apoio de negócios, que em 2018 abriga cerca de 12 empresas jovens (pré-incubação) ou estabelecidas (incubação). Cerca de seis empresas com ligação de modelos de negócios de AGTech já foram graduadas (passaram pela incubação) na incubadora nos últimos dez anos. Este movimento proporciona a geração de empregos diretos e indiretos, além de dezenas de estágios extra curriculares e obrigatórios para acadênmicos dos cursos de graduação da FZEA/USP.

O núcleo dessas empresas gira em torno da biotecnologia, agronegócio de precisão e tecnologia de informação, mas também crescem em número e tamanho empresas focadas em Energia e Ambiente e Serviços.

\subsubsection{Parc Científic de la Universitat de València - Espanha}

O Parque da Ciência da Universitat de València foi oficialmente inaugurado em 2009 como uma iniciativa estratégica da Universidade de Valência (UV). Sua missão 
não é apenas fortalecer as atividades de P\&D da instituição, mas também promover a inovação apostando na gênese de projetos de negócios baseados no conhecimento.

O PCUV possui uma área científica composta por seis institutos de pesquisa, dois centros únicos e uma importante infraestrutura de serviços e equipamentos para pesquisa e uma área de negócios, que atualmente abriga cerca de cem empresas jovens ou estabelecidas. Em 2016, foram localizadas 85 empresas, gerando mais de 573 empregos diretos, em sua maioria altamente qualificados.

O núcleo dessas empresas gira em torno da biotecnologia, tanto no seu papel de saúde agroalimentar, mas também crescem em número e tamanho empresas focadas em Energia e Ambiente, Nanotecnologia, Materiais e Serviços Avançados.

A Fundació Parc Científic Universitat de València (FPCUV) administra a área de negócios do PCUV, fornecendo: serviços de incubação para novas empresas, serviços de alto valor agregado às empresas mais consolidadas para melhorar sua competitividade e internacionalização.

\subsubsection{Universidad Autónoma de Barcelona - Espanha}

O Parque de Recerca UAB (PRUAB) é uma fundação sem fins lucrativos criada em 2007 pela Universidade Autônoma de Barcelona (UAB), o Conselho Superior de Pesquisas Científicas (CSIC) e do Instituto de Agricultura e Alimentação Research (IRTA).

Sua missão é promover e melhorar as actividades de transferência de tecnologia e experiência de seus membros, promover o empreendedorismo através da criação de novas empresas com base em pesquisas e geralmente facilitar a interação entre a investigação, as empresas ea sociedade. Desde a sua criação, o PRUAB tem trabalhado para ser um agente chave no sistema de inovação do seu território de influência.

Nesse sentido, o Parque de Pesquisas da UAB realiza diferentes atividades para promover o surgimento e o crescimento de projetos empresariais decorrentes da atividade de pesquisa. Além disso, também oferece serviços de alto valor agregado às empresas mais consolidadas para melhorar sua competitividade e financiamento. 


\subsubsection{Universidad Autónoma de Occidente - Colômbia}

O Centro de Inovação Educacional em Engenharia é uma unidade acadêmica responsável por gerar espaços, experiências e recursos para mediar processos de ensino, aprendizagem, exploração e experimentação nos quais é promovido:

- A criação de uma forte cultura em torno da tecnologia, design, empreendedorismo e inovação nos negócios, nas linhas sociais e educacionais.

- O desenvolvimento de competências genéricas em engenharia que permitem entregar soluções criativas com alto valor percebido pelo meio ambiente.

- O design, a implantação e a transferência de experiências de aprendizado inovadoras dentro e fora da sala de aula.

Em colaboração com o Centro Institucional de Empreendedorismo Corporativo CIEE, da Universidad Autonoma de Occidente (UAO) é a unidade acadêmica especializada em diversos assuntos relacionados com a promoção, apoio, aconselhamento, formação acadêmica, inovação e investigação, no domínio do empreendedorismo empresarial.

Nesta ordem de ideias, nos últimos dois anos apoiou, em média, 40 projetos empresariais a cada seis meses, este apoio consiste em ajudar os empresários na estruturação do seu plano de negócios. Destes projetos, em aproximadamente 10\%, eles contam com um acompanhamento mais especializado que busca a obtenção de recursos financeiros e o start-up da empresa.

\subsubsection{Universidad Parque Científico e Biotecnológico do Pacífico - Colômbia}

O Parque Biopacífico é uma área de excelência e inovação, um ponto de relacionamento estratégico entre as universidades, investigação e desenvolvimento tecnológico, empresas públicas e privadas, organizações colombianas e estrangeiras e agências do governo central e regional para promover e desenvolver Cultura de inovação e competitividade.

Entre as finalidades do parque estão: promover projetos que geram aumento do valor acrescentado e novas oportunidades de mercado aberto; ser uma transferência 
de tecnologia de núcleo que dá origem a negócios, para aumentar a produção e produtividade agrícola e industrial; promover a criação e o crescimento de empresas inovadoras; apoiar a organização eo desenvolvimento de cadeias de valor e formas de organização como clusters, organizações de produtores e redes de conhecimento. Por que vai oferecer serviços de alto valor que suportam o desenvolvimento, investigação e inovação. Ele também irá reforçar a formação de pesquisadores, empresários inovadores, técnicos e tecnólogos.

Os promotores da Corporação são: Ministério da Agricultura e Desenvolvimento Rural, Governo do Valle del Cauca, município de Palmira, Câmara de Comércio Palmira, Centro Internacional de Agricultura Tropical (CIAT), o Instituto Colombiano Agropecuário (ICA), Corporação de Pesquisa colombiano Agropecuaria (Corpoica), Universidade Nacional, Universidad del Valle. O parque também conta com o apoio da Universidade Pontifícia Bolivariana, que é o seu parceiro e apoiada pelos EstadosColciencias.

\subsubsection{Universidad de La Frontera - Chile}

A IncubatecUFRO, Incubadora de Empresas na Universidade Pública de La Frontera, nasceu em novembro de 2001 na sequência de um programa da Corporação de Desenvolvimento do Chile para a revitalização do empresário sob a asa do ecossistema Universidade de La Frontera.

Desde então, a IncubatecUFRO tem gerado estruturas e ações de apoio à criação e consolidação de iniciativas empresariais inovadoras, integrando os esforços do setor público, acadêmico e privado, sendo concedidos por CORFO 2014 e 2015 como a melhor incubadora de Chile.

A IncubatecUFRO, visa facilitar e acelerar o crescimento do negócio através de serviços de consultoria para o desenvolvimento e fortalecimento de modelos de negócios, planos de marketing, finanças, prospecção de clientes, validação de mercado, prototipagem e geração de competências empresariais; além de dar acesso aos seus fundos de capital semente incubados através do seu Fundo Incubainvest e outros fundos disponíveis no setor público e privado. 


\subsubsection{Universidad de Técnica Particular de Loja - Equador}

O Centro de Empreendedorismo PRENDHO da Universidade Técnica Particular de Loja é uma incubadora e aceleradora de empresas.

Conta com uma equipe multidisciplinar, que assessora e apoia os empreendedores que necessitam de suporte nas diferentes fases do modelo de incubação e aceleram o processo de crescimento das empresas que já se formaram e precisam se expandir no mercado.

\subsubsection{Universidad Nacional de La Plata - Argentina}

Criada em 2014, a incubadora MINERVA foi projetada para acelerar o processo de criação de negócios sustentáveis nascidos das ideias dos alunos da Universidade Nacional de La Plata (UNLP), articulando suas ações junto ao Gabinete de Ligação Tecnológica com as diferentes Unidades Acadêmicas e suas respectivas Unidades de Desenvolvimento Empresarial.

É um espaço de coworking onde estudantes e pesquisadores participam de atividades organizadas com foco no empreendedorismo. Neste espaço, eles recebem assistência permanente, local de trabalho e as virtudes das redes e do capital social que a Universidade tem à sua disposição.

O objetivo é propor um local de trabalho colaborativo e interdisciplinar para o desenvolvimento empreendedor de alunos da UNLP cujo objetivo é a criação de uma empresa.

\subsubsection{Universidade de Lisboa - Portugal}

A INOVISA foi criada em 2005 pelo Instituto Superior de Agronomia (ISA Universidade de Lisboa), com o objetivo de apoiar seus professores, pesquisadores e estudantes na criação de seus projetos de negócios. A INOVISA está localizada na Tapada da Ajuda e integrada no campus universitário da Universidade de Lisboa. Linhas de ação:

- BOOST - Empreendedorismo e Desenvolvimento de Negócios: apoio a projetos empresariais que desenvolvam produtos ou serviços baseados em 
conhecimento e tecnologia, com foco nos setores agrícola, alimentício e florestal.

- LINK - Transferência de Conhecimento e Tecnologia: Promove a conexão entre o ambiente científico e acadêmico e o setor empresarial do setor agrícola, alimentar e florestal de maneira ampla e imparcial.

- SPREAD - Comunicação Digital do Conhecimento: a comunicação digital desempenha e a necessidade de comunicar conhecimento e tecnologia de forma mais assertiva e eficaz no setor agrícola, alimentar e florestal.

- GLOBAL - Cooperação, Desenvolvimento e Internacionalização: articula e promove iniciativas a nível internacional com cada uma das áreas do INOVISA, com especial enfoque na Europa e países de língua portuguesa.

\subsection{Fundamentos para a elaboração do questionário e da entrevista semiestruturada}

Os respondentes tiveram acesso aos formulários online que foram divulgados pela coordenação do projeto de pesquisa, apoiando-se em comunicação clara e transparente dos objetivos a serem alcançados e com absoluta garantia de que os dados preenchidos, de forma voluntária, são de natureza sigilosa e a preservar os direitos daqueles que entenderem importante fazer seus depoimentos e entrevistas. Para tanto, o projeto de pesquisa foi submetido e aprovado na Plataforma Brasil, sob CAEE n 87688718.2.0000.5422 (ANEXO 1).

A inovação é um processo contínuo. As organizações realizam constantemente mudanças em produto e processo e buscam novos conhecimentos, e é mais difícil medir um processo dinâmico do que uma atividade estática. Por isso, a importância da utilização de indicadores que evidenciam os fatores que influenciam as atividades de inovação e seus impactos (OCDE, 1997).

O questionário, elaborado para os Coordenadores das incubadoras da Rede AGROINNCUBA, buscou identificar as características organizacionais e o processo de acompanhamento das empresas nelas incubadas. As características organizacionais e a estrutura das incubadoras influenciam a capacidade de inovação das organizações. Segundo Matthew e Sharon (2000), a estrutura de uma empresa é 
um fator de sucesso e incluem sub dimensões com a estratégia da empresa, a sua orientação para a competitividade, as políticas específicas de cada empresa, a estrutura legal, a localização geográfica, os relatórios de atividade atualizados e técnicas de controle financeiro, tais considerações tem o mesmo valor para as próprias incubadoras.

Através dos questionários, foi possível realizar um planejamento da coleta de informações da entrevista por meio da elaboração de um roteiro com perguntas que atendiam os objetivos pretendidos de analisar o discurso acerca do ecossistema de inovação no qual as universidades e incubadoras estão inseridas. Assim, o roteiro desempenhou o papel de ser um meio para o pesquisador se organizar para 0 processo de interação com o informante (MANZINI, 2003).

\subsection{Análise dos dados da pesquisa}

Os dados coletados do questionário fechado foram tabulados e analisados através de técnica de análise estatística multivariada. A análise multivariada tem suas raízes das técnicas das análises univariadas e bivariadas (HAIR et al., 2005). Ainda segundo o autor, os métodos multivariados são escolhidos de acordo com os objetivos da pesquisa, pois sabe-se que a análise multivariada é uma análise exploratória de dados, prestando-se a gerar hipóteses, e não tecer confirmações a respeito dos mesmos, o que seria uma técnica confirmatória, como nos testes de hipótese, nos quais se tem uma afirmação a respeito da amostra em estudo. Embora, às vezes, possa ser utilizada para confirmação dos eventos.

Dentre os métodos de análise multivariada, a análise de componentes principais (ACP) é uma técnica matemática que consiste em transformar um conjunto de variáveis originais em outro conjunto de variáveis de mesma dimensão denominadas de componentes principais (VICINI, 2005). A análise de componentes principais tem por objetivo descrever os dados contidos num quadro indivíduos-variáveis numéricas: $p$ variáveis serão mediadas com $n$ indivíduos. Esta é considerada um método fatorial, pois a redução do número de variáveis não se faz por uma simples seleção de algumas variáveis, mas pela construção de novas variáveis sintéticas, obtidas pela combinação linear das variáveis inicias, por meio dos fatores (BOUROCHE, 1982). 
A ACP possibilita investigações com um grande número de dados disponíveis, além da identificação das medidas responsáveis pelas maiores variações entre os resultados, sem perdas significativas de informações. Ainda, transforma um conjunto original de variáveis em outro conjunto: os componentes principais $(\mathrm{CP})$ de dimensões equivalentes. Essa transformação, em outro conjunto de variáveis, ocorre com a menor perda de informação possível, sendo que também busca eliminar algumas variáveis originais que possua pouca informação. Essa redução de variáveis só será possível se as $p$ variáveis iniciais não forem independentes e possuírem coeficientes de correlação não-nulos.

O primeiro componente principal é a combinação linear com variância máxima, o segundo componente principal é a combinação linear com variância máxima em uma direção ortogonal ao primeiro componente principal, e assim por diante. Em geral, os componentes principais definem dimensões diferentes daquelas definidas por funções discriminantes ou variáveis canônicas (ALVIN, 2002).

A meta da análise de componentes principais é abordar aspectos como a geração, a seleção e a interpretação das componentes investigadas. Carrer (2000) resumiu que "a técnica em Componentes Principais tem o objetivo de resumir as informações contidas em um número relativamente grande de variáveis em um número mais reduzido de variáveis não correlacionadas, chamadas fatores, facilitando a análise". Em geral as variáveis que se prestam a este tipo de análise são de natureza quantitativa e se utilizam variáveis centradas-reduzidas.

Para a aplicação da técnica de Componentes Principais foi utilizado o Software Estatístico Minitab Inc Versão 18.

Paralelamente à análise estatística dos dados que compõem essa pesquisa, foram aproveitados depoimentos realizados por atores que coordenam cada uma das incubadoras e parques da Rede AGROINNCUBA, de forma a complementar as informações quantitativas trabalhadas.

De acordo com Godoy (1995), a pesquisa que acrescenta informações qualitativas trata melhor a compreensão de um determinado fenômeno, no contexto em que ocorre e do qual é parte. Para tanto, o pesquisador deve ir a campo captar tal fenômeno, a partir da perspectiva das pessoas envolvidas, considerando os diferentes pontos de 
vistas, neste caso, vários tipos de dados são coletados e analisados para que se entenda a dinâmica deste fenômeno.

Neste contexto, as entrevistas são fundamentais quando se deseja mapear práticas, crenças, valores e sistemas classificatórios de universos sociais específicos, mais ou menos bem delimitados, em que os conflitos e contradições não estejam claramente explicitados. Pois elas permitem ao pesquisador fazer uma espécie de mergulho em profundidade, coletando indícios dos modos como cada um daqueles sujeitos percebe e significa sua realidade e levantando informações consistentes que permitem descrever e compreender a lógica que preside as relações que se estabelecem no interior daquele grupo, o que, em geral, é mais difícil obter com outros instrumentos de coleta de dados (DUARTE, 2004).

Segundo Rosar e Arnoldi (2006), em relação às outras técnicas de questionários, formulários, leitura documentada e observação participativa, as entrevistas apresentam vantagens que podem aqui ser evidenciadas:

- Permitem a obtenção de grande riqueza informativa - intensiva, holística e contextualizada - por serem dotadas de um estilo especialmente aberto, já que se utilizam de questionamentos semiestruturados;

- Proporcionam ao entrevistador uma oportunidade de esclarecimentos, junto aos segmentos momentâneos de perguntas e respostas, possibilitando a inclusão de roteiros não previstos, sendo esse um marco de interação mais direta, personalizada, flexível e espontânea;

- Cumprem um papel estratégico na previsão de erros, por ser uma técnica flexível, dirigida e econômica que prevê, antecipadamente, os enfoques, as hipóteses e outras orientações úteis para as reais circunstâncias da investigação, de acordo com a demanda do entrevistado, propiciando tempo para a preparação de outros instrumentos técnicos necessários para a realização, a contento, da entrevista.

Para Manzini (1990), a entrevista semiestruturada está focalizada em um assunto sobre o qual se confecciona um roteiro com perguntas principais, complementadas por outras questões inerentes às circunstâncias momentâneas à entrevista. Para o 
autor, esse tipo de entrevista pode fazer emergir informações de forma mais livre e as respostas não estão condicionadas a uma padronização de alternativas.

O discurso presente na fala dos entrevistados não é tratado apenas como transmissor de informações, mas também como o efeito de sentido entre os locutores, por meio do qual se faz a mediação entre o homem e sua realidade natural e deve-se levar em consideração o contexto histórico, socioeconômico e cultural do enunciador (CARRIERI et al., 2006).

As entrevistas com os gestores das incubadoras avaliadas neste estudo, após serem realizadas no segundo encontro da AGROINNCUBA realizado na cidade de Valência, Espanha, foram transcritas e passadas pela conferência de fidedignidade, em que a gravação foi ouvida tendo o texto transcrito em mãos, sendo acompanhada e conferida cada frase, mudanças de entonação, interjeições, interrupções e etc..

Sendo assim, os dados da pesquisa são resultado da ordenação do material empírico coletado/construído no trabalho de campo, que passa pela interpretação dos fragmentos dos discursos dos entrevistados, organizados em torno de categorias ou eixos temáticos, e do cruzamento desse material com as referências teórico/conceituais que orientam o olhar do pesquisador (DUARTE, 2004).

Maingueneau (2004) definiu a análise de discurso como uma técnica que, em vez de proceder a análise linguística do texto em si ou a uma análise psicológica de seu contexto, visa articular sua enunciação sobre um certo lugar social ou ideologia. Para tal, buscou-se interpretar o que foi dito pelos Coordenadores das incubadoras, a forma que o discurso foi construído, o seu contexto e a natureza dos recursos utilizados para a construção desses discursos, ao mesmo tempo em que se procura interpretar os dados de natureza quantitativa oriundos do preenchimento de formulários com dados primários da Rede AGROINNCUBA. 


\section{RESULTADOS E DISCUSSÃO}

\subsection{Análise do Questionário aplicado aos Coordenadores das incubadoras}

A partir dos dados extraídos das 8 entrevistas online realizadas com os Coordenadores das incubadoras, foi pré-selecionado um conjunto de 22 variáveis, que dizem respeito a características de estrutura, organizacionais e práticas desenvolvidas pelas incubadoras. Segue a lista das variáveis originais.

\section{Variáveis originais geradas para dados sobre as Incubadoras:}

V01=Tempo de existência da incubadora: em anos

V02=Status do Modelo de auto-avaliação: 0 (para não possui), 1 (para em planejamento), 2 (para em desenvolvimento) e 3 (para estabelecido)

V03= Status da realização de ciclos regulares de Planejamento Estratégico: 0 (para não possui), 1 (para em planejamento), 2 (para em desenvolvimento) e 3 (para estabelecido)

V04= Status do desenvolvimento de Programas de Formação Continuada: 0 (para não possui), 1 (para em planejamento), 2 (para em desenvolvimento) e 3 (para estabelecido)

V05= Status da promoção de eventos temáticos de Empreendedorismo: 0 (para não possui), 1 (para em planejamento), 2 (para em desenvolvimento) e 3 (para estabelecido)

V06= Status da aproximação de fontes de fomento junto aos empreendedores: 0 (para não possui), 1 (para em planejamento), 2 (para em desenvolvimento) e 3 (para estabelecido)

V07= Status do programa de acompanhamento/interação com Empresas Graduadas: 0 (para não possui), 1 (para em planejamento), 2 (para em desenvolvimento) e 3 (para estabelecido)

V08=Ambiente acadêmico e/ou centro de pesquisa favorável ao desenvolvimento de novos negócios: 0 (para ausente) e 1 (para presente) 
V09= Localização estratégica: 0 (para ausente) e 1 (para presente)

V10 $=$ Proximidade de centros tecnológicos e incubadoras temáticas de sucesso consolidadas: 0 (para ausente) e 1 (para presente)

V11 = Infraestrutura e serviços de qualidade: 0 (para ausente) e 1 (para presente)

V12= Networking com parceiros altamente qualificados: 0 (para ausente) e 1 (para presente)

V13= Forte apoio técnico/gerencial às empresas incubadas: 0 (para ausente) e 1 (para presente)

V14= Excesso de expectativa em relação a sustentabilidade financeira: 0 (para ausente) e 1 (para presente)

V15= Dificuldade de acesso à credito e financiamento: 0 (para ausente) e 1 (para presente)

V16= Pouca autonomia gerencial: 0 (para ausente) e 1 (para presente)

V17= Inadequação das instalações: 0 (para ausente) e 1 (para presente)

V18= Falta de recursos para manutenção e expansão: 0 (para ausente) e 1 (para presente)

V19= Baixa oferta de capacitação empreendedora: 0 (para ausente) e 1 (para presente)

V20 = Quantidade de empresas incubadas: em unidade

V21= Quantidade de empresas pré-incubadas: em unidade

V22= Tempo médio de graduação: em anos

Após validações testes com os dados da planilha original com 22 variáveis da pesquisa, foram selecionadas, estrategicamente, um novo conjunto de sete variáveis que expressaram valores significativos e máximos na matriz de correlação gerada ao final da análise. Segue a nova lista de variáveis selecionadas na geração da Análise Fatorial em Componentes Principais, rotação Varimax. 
Variáveis selecionadas para a análise dos dados sobre as Incubadoras:

V01=Tempo de existência da incubadora: em anos

V05= Status da promoção de eventos temáticos de Empreendedorismo: 0 (para não possui), 1 (para em planejamento), 2 (para em desenvolvimento) e 3 (para estabelecido)

V08=Ambiente acadêmico e/ou centro de pesquisa favorável ao desenvolvimento de novos negócios: 0 (para ausente) e 1 (para presente)

V11 = Infraestrutura e serviços de qualidade: 0 (para ausente) e 1 (para presente)

V12= Networking com parceiros altamente qualificados: 0 (para ausente) e 1 (para presente)

V13= Forte apoio técnico/gerencial às empresas incubadas: 0 (para ausente) e 1 (para presente)

V20 = Quantidade de empresas incubadas: em unidade

Aplicando-se o método da Análise Multivariada Fatorial em Componentes Principais, optou-se pela utilização do critério de Kaiser (1958), que considera somente os componentes principais com os autovalores calculados e expressivos.

Os demais fatores foram desprezados na interpretação, pois passam a representar valores não importantes para a explicação da variância total dos dados (Figura 8). Observa-se que juntos, os cinco fatores calculados explicam mais de $95 \%$ da variação dos dados (Tabela 5). Este resultado é considerado muito adequado para a explicação da variância total dos dados da pesquisa. 
Tabela 4 - Resultados de autovalores e \% das variâncias total e acumulada para os 8 indivíduos (incubadoras) e 7 variáveis relacionadas a dados fornecidos pelos Coordenadores das incubadoras da Rede AGROINNCUBA.

\begin{tabular}{|cccc|}
\hline Fatores & Autovalores & $\begin{array}{c}\text { Proporção da } \\
\text { Variância por } \\
\text { Fator }\end{array}$ & $\begin{array}{c}\text { Proporção da } \\
\text { Variância } \\
\text { Acumulada }\end{array}$ \\
\hline 1 & 1,6901 & 0,241 & 0,241 \\
\hline 2 & 1,4305 & 0,204 & 0,445 \\
\hline 3 & 1,4112 & 0,202 & 0,647 \\
\hline 4 & 1,3912 & 0,199 & 0,846 \\
\hline 5 & 0,7634 & 0,109 & 0,955 \\
\hline
\end{tabular}

Fonte: Dados da pesquisa.

Figura 8 - Diagrama dos autovalores para os fatores calculados, considerando-se os 8 indivíduos (incubadoras) e 7 variáveis relacionadas a dados fornecidos pelos Coordenadores das incubadoras da Rede AGROINNCUBA.

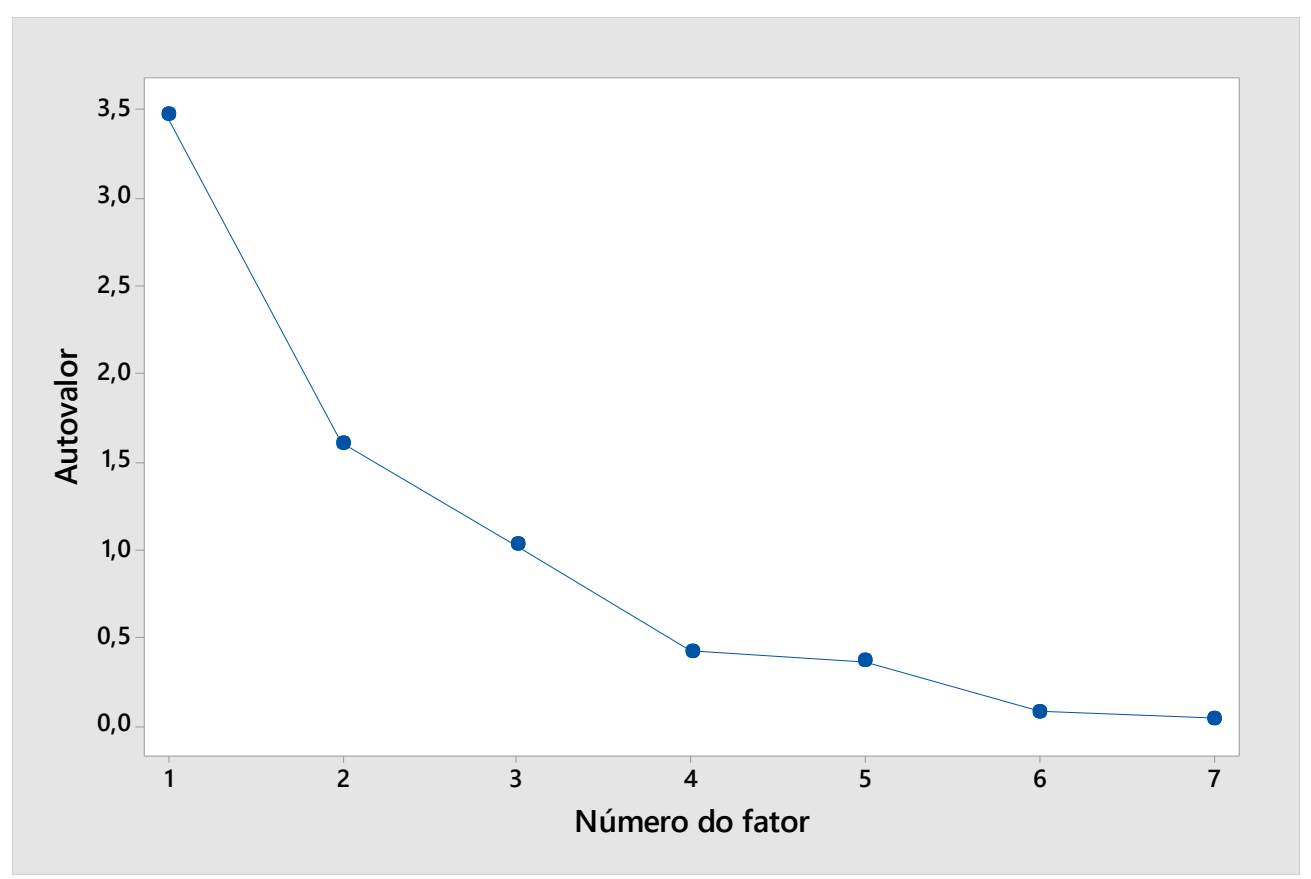

Fonte: Dados da pesquisa. 
As combinações lineares das variáveis utilizadas constituíram novos vetores associados aos eixos fatoriais. Assim, com o uso dos fatores (eixos fatoriais), podese interpretar o problema de forma mais pragmática (KAGEYAMA e SILVEIRA, 1997).

Tabela 5 - Resultados de coeficientes de correlação para os cinco fatores calculados, considerando-se os 8 indivíduos (incubadoras) e 7 variáveis relacionadas a dados fornecidos pelos Coordenadores das incubadoras da Rede AGROINNCUBA.

\begin{tabular}{|c|c|c|c|c|c|}
\hline Variável & Fator 1 & Fator 2 & Fator 3 & Fator 4 & Fator 5 \\
\hline 1 & 0,750 & 0,121 & 0,299 & 0,085 & $-0,395$ \\
\hline 5 & 0,093 & 0,135 & 0,212 & 0,945 & $-0,185$ \\
\hline 8 & $-0,980$ & $-0,030$ & $-0,150$ & $-0,091$ & 0,026 \\
\hline 11 & $-0,105$ & $-0,977$ & $-0,025$ & $-0,168$ & $-0,075$ \\
\hline 12 & 0,222 & $-0,214$ & 0,432 & 0,464 & $-0,707$ \\
\hline 13 & 0,296 & $-0,008$ & 0,887 & 0,238 & $-0,256$ \\
\hline 20 & 0,099 & $-0,630$ & 0,530 & 0,427 & $-0,034$ \\
\hline Autovalor & 1,6901 & 1,4305 & 1,4112 & 1,3912 & 0,7634 \\
\hline \% Var. & 0,241 & 0,204 & 0,202 & 0,199 & 0,109 \\
\hline \% Var. Ac. & 0,241 & 0,445 & 0,647 & 0,846 & 0,955 \\
\hline
\end{tabular}

Fonte: Dados da pesquisa.

Os coeficientes de correlação entre as variáveis selecionadas e os fatores podem ser visualizados na Tabela 6. Os índices que se apresentam marcados, em negrito, estão acima de $\mathbf{0 , 6 0}$ de correlação e facilitam a visualização dos resultados.

Foi utilizada nesta análise, uma rotação dos eixos através da transformação ortogonal denominada VARIMAX, com o objetivo da obtenção de uma estrutura simples, isto é, obter uma nova matriz $n \times m$ de coeficientes dos fatores de maneira que os valores absolutos dos elementos de cada coluna dessa matriz se aproximem, na medida do possível, de zero ou 1 (KAISER, 1958).

Isto facilita a interpretação dos fatores, que após a rotação deverão apresentar correlações mais fracas ou mais fortes com determinado conjunto de variáveis. Como lembra Hoffmann (1992), a "rotação ortogonal não altera a comunalidade das variáveis". 
O primeiro fator apresenta correlação positiva relacionada ao tempo de existência da incubadora e a presença de ambientes de inovação e pesquisa junto a universidades e institutos de pesquisa favoráveis ao desenvolvimento de novos negócios (Variáveis 1 e 8). Seu autovalor calculado é de 1,6901 e explica individualmente $24,1 \%$ da variância total dos dados.

Esse fator sugere evidências que as incubadoras que promovem mais oportunidades para o DESENVOLVIMENTO TECNOLÓGICO do processo produtivo e oferecem aos novos empreendedores, além de espaço físico e serviços de escritório, o apoio administrativo, aconselhamento e consultoria gerencial e de marketing necessários, tem maior facilidade em buscarem resultados junto com as empresas residentes. Existe um possível estabelecimento de uma virtuosa espiral de inovação que permeia a todos que estão envolvidos no sistema.

Neste sentido, fica sugerida a comprovação da sensação empírica de que é benéfico para a obtenção de resultados empresariais ao ecossistema, a proximidade da incubadora e parques tecnológicos/científicos com ambientes que geram inovação, representados em geral pelas iniciativas de pesquisa e transferência tecnológica realizadas no ambiente acadêmico.

Isso confirma que os ecossistemas de inovação geradores de negócios inovadores são originados, normalmente, da relação sinérgica de ambientes que produzem ciência e tecnologia, tais como universidades institutos de pesquisa e que mantêm relações de efetiva cooperação com o setor produtivo (KOLOSKY; SPERONI e GAUTHIER, 2015).

Os canais e as redes de comunicação pelas quais essas informações circulam inserem-se numa base social, política e cultural que guia as atividades e capacitações inovadoras. A inovação é vista como um processo dinâmico em que o conhecimento é acumulado por meio do aprendizado e da interação. Esses conceitos foram introduzidos inicialmente em termos de sistemas nacionais de inovação, mas eles se aplicam também a sistemas regionais e internacionais. Juan Antonio Raga Esteves, Diretor do Parque Científico da Universidade de Valência, afirma que:

"A terceira missão da Universidade que surgiu evoluindo dentro das funções das universidades clássicas é um desafio que está em permanente definição. Realmente, na Universidade tem se tentado 
abordar uma contribuição direta para a sociedade além de treinar o pessoal, além de obter novas descobertas científicas. Portanto, essa contribuição direta para a sociedade pode ser dada de muitas maneiras. Há diferentes maneiras de se conceber que a terceira missão da Universidade passa por questões sociais e culturais e que algumas acontecem precisamente apostando na inovação do ponto de vista do impacto no tecido econômico e social do meio ambiente através da gênese das empresas".

O segundo fator traz a evidência da INFRAESTRUTURA do ecossistema diretamente constituído pela quantidade de empresas residentes, apresentando correlações elevadas relacionadas à importância da capacidade de alavancar recursos e serviços de qualidade para oferecer às empresas incubadas e aos demais atores do ecossistema (Variáveis 11 e 20). Seu autovalor calculado é de 1,4305 e explica individualmente $20,4 \%$ da variância total dos dados.

A exemplo disso, Autio e Klofsten (1998), baseados em entrevistas com gerentes de incubadoras em dois parques científicos europeus, também identificaram desafios em relação a infraestrutura e localização, tais como: a) ocorrência de infraestruturas inadequadas, em termos de flexibilidade, disponibilidade de espaços e instalações. As empresas poderiam precisar de espaços flexíveis que não representam uma restrição em caso de ampliação ou de mudança de prédio no parque; (b) a não permissão de certas instalações de porte industrial ou de manuseio de certas matérias-primas e resíduos; c) a distância excessiva das instalações e instituições de ensino superior ou centros de pesquisa dificultando a transferência de tecnologia.

Desta natureza, a fala de "Economia baseada em conhecimento" e suas variações são bastante utilizadas para descrever tendências em economias avançadas no sentido de maior dependência do conhecimento, informação e altos níveis de especialização e a crescente necessidade de pronto acesso a esses fatores pelos setores privado e público. O conhecimento e a tecnologia tornaram-se cada vez mais complexos, aumentando a importância das interações entre empresas e outras organizações como uma forma de adquirir conhecimento especializado. Um desenvolvimento econômico paralelo é o crescimento da inovação em serviços nas 
economias avançadas (OCDE, 1997). Para Carlos Valero Santiago, coordenador do Parc de la Universidad Autónoma de Barcelona, neste cenário o papel da universidade é:

“(..) reconhecer quais são os desafios da sociedade e com a contribuição do que seria do elemento da sociedade para empresas, instituições etc.. Ser capaz de responder a esses desafios, neste caso, é importante o fato de ser bidirecional, não apenas da universidade para a sociedade, mas para ambas as direções”.

Mais do que a oferta de espaço e infraestrutura a custos abaixo dos praticados no mercado, o objetivo da incubadora é sustentar a viabilidade das empresas incubadas. Neste sentido, grande importância é dada ao processo de acompanhamento aos projetos incubados. Segundo Bizotto et al. (2002), quando o processo de acompanhamento e orientação é de boa qualidade, os problemas enfrentados pelas empresas incubadas são rapidamente identificados e solucionados. Para os autores citados, estes problemas estão relacionados às dificuldades técnicas, à falta de experiência, às dificuldades para penetração no mercado e, às dificuldades no gerenciamento do projeto.

O número de empreendimentos graduados com sucesso também é um indicador importante, conforme observado por Morais (1998) "uma das formas de analisar o sucesso de uma incubadora é observar o número de empresas, por ela graduadas, que se firmaram no mercado" em um período superior a 2 anos após a incubação.

O terceiro fator apresenta correlação positiva relacionado com a variável 13, ligada à oferta de recursos de CAPACITAÇÃO EM GESTÃO, evidenciando, não só a importância da qualidade do projeto da empresa em si, mas também de como essas práticas de gestão podem impulsionar as empresas incubadas. Seu autovalor calculado é de 1,4112 e explica individualmente $20,2 \%$ da variância total dos dados.

Para Lalkaka (2003), a incubadora é a denominação utilizada para definir o espaço institucional para apoiar a transformação de empresários potenciais em empresas crescentes e lucrativas. Enquanto que, Andrade e Torkomian (2001) definem Educação Empreendedora combinada com ações de gestão do empreendimento, como um processo que visa ao desenvolvimento de pessoas no domínio da 
identificação e aproveitamento de oportunidades, a capacidade de realização, contribuindo assim para a geração de valores financeiros, sociais e culturais para a sociedade que o indivíduo está inserido.

"O empreendedorismo, como uma área de negócios, busca entender como surgem as oportunidades para criar algo novo (novos produtos ou serviços, novos mercados, novos processos de produção ou matérias-primas, novas formas de organizar as tecnologias existentes); como são descobertas ou criadas por indivíduos específicos que, a seguir, usam meios diversos para explorar ou desenvolver essas coisas novas, produzindo assim uma ampla gama de efeitos." (BARON; SHANE, 2007).

Neste sentido, é interessante registrar a posição de Edwin Giraldo Henao, Coordenador do Parque agroindustrial, científico y tecnológico del pacifico/Colômbia, que afirma que o desafio das instituições está concentrado em como o empreendedorismo é promovido para ser capaz de transferir e torná-lo uma realidade:

"Eu vou falar especificamente sobre o que aconteceu na Colômbia em torno do empreendedorismo. As estratégias não têm sido fortes o suficiente para que as empresas que são acompanhadas tenham um sucesso esperado, a empresa tem que atacar da base, da cultura, você tem que moldar estrategicamente a gestão curricular das instituições. Se pensarmos que as instituições têm um perfil empreendedor, temos que atacar essa gestão curricular a partir do conceito e do contexto para começar a formar as habilidades que precisamos para que um verdadeiro empreendedorismo seja evidenciado".

Na sequência, o quarto fator aponta correlação alta e positiva com a realização de ciclos regulares na promoção de eventos com temática voltada para a FORMAÇÃO EMPREENDEDORA na incubadora e com a oportunidade de proximidade de centros tecnológicos e incubadoras temáticas de sucesso consolidadas (Variável 5). Seu autovalor calculado é de 1,3912 e explica individualmente 19,9\% da variância total dos dados.

A ANPROTEC (1999) relaciona a criação de incubadoras como o estímulo à cooperação entre universidades e a sociedade, com a otimização do potencial 
regional no desenvolvimento econômico, social, tecnológico e, principalmente, com o incentivo ao empreendedorismo.

Esse achado vai também ao encontro das recomendações de muitos autores citados (ETZKOWITZ et al., 2000; BATISTA, 2004; LEMOS, 2009; PLONSKI e CARRER, 2009; CARRER, 2010; OECD, 2010; JACKSON, 2011; SPOLIDORO, 2011; SCHLEMM, 2014 e AUDY, 2017).

Parte-se do princípio que as Universidades assumem um novo desafio, o de atuarem como vetores do desenvolvimento econômico e social da sociedade, ampliando suas missões básicas, de ensino e pesquisa. A inovação emerge como o motor desse processo de transformação, levando a pesquisa à sociedade, atuando como fonte de resolução de problemas e abertura de novas possibilidades. Nesse local, os ambientes de inovação, sejam mecanismos de geração de empreendimentos, sejam áreas de inovação, emergem como o locus onde está inserido o processo de atuação das universidades. Isso se manifesta com muita força, na conexão e interação com os meios empresariais, governamentais e a própria sociedade (OCDE, 1997). De acordo com Vicent Clemente Ciscar, responsável operacional, do Parque Científico da Universidade de Valência:

"Tradicionalmente tem sido falado de três missões: a primeira ligada a parte formativa; depois para gerar novos conhecimentos que seriam obtidos no esforço de investigação; em seguida, nos últimos anos falamos sobre uma terceira missão, que entendemos como uma transferência compreendida em uma forma ampla em que seria a parte da divulgação, um compromisso social e nós, do ponto de vista do parque e incubadoras entendemos que a fase de terceira missão está muito relacionada com a transferência de resultados da pesquisa ou ver como todo esse conhecimento que é gerado apoia a sociedade, através de produtos ou serviços que são geralmente trabalhados a partir de empresas".

Para a Ana Julia Fernández Duran, Coordenadora de Gestão da Universidad de la Frontera, que também trabalha na incubadora da INCUBATECUFRO: 
"A terceira missão da universidade é a relação com o meio ambiente, e como o conhecimento agrega valor à comunidade regional e nacional. Nossa principal aspiração é que o que é feito dentro da universidade gere impacto na comunidade e seja valorizado por ela."

O quinto fator apresenta correlação positiva com a variável (12) que se relaciona especificamente com o dimensionamento da oportunidade que a incubadora oferece de NETWORKING com parceiros altamente qualificados. Seu autovalor calculado é de 0,7634 e explica individualmente $10,9 \%$ da variância total dos dados.

Esse fator evidencia o papel da incubadora no Ecossistema de Inovação, ambiente no qual há interdependência de atores que buscam um objetivo comum, tais como, criar ou capturar valor a partir de uma oportunidade percebida. Esse achado coincide com vários autores (LI, 2009; BASOLE, 2009; CHESBROUGH et al., 2014) que consideraram o networking ou a estratégia de inovação ocasionada pela interação entre os atores reunidos (ROTHWELL, 1995; AHUJA, 2000; BELLAVER, 2005; CATHARINO, DAMIAO e ZOUAIN, 2006; AUTIO e THOMAS, 2013 e SCHLEMM, 2014) como um dos principais benefícios entre os empreendedores em um ecossistema de inovação, tal qual o papel desempenhado pelas incubadoras da AGROINNCUBA, independentes de atuarem ou não como uma rede.

O próprio significado de networking está relacionado a capacidade de estabelecer uma rede de contatos. Por sua vez, a teoria de rede também oferece uma abordagem de interdependência (GULATI, 1998), o que torna importante a discussão sobre as semelhanças e distinções entre a perspectiva de ecossistema e de rede. Segundo Moore (1993), a rede por si só não abrange a característica de dinamicidade que ocorre nas interconexões entre os atores de uma rede. Desse modo, a analogia de ecossistema retrata bem essa ideia de algo orgânico, onde existe além da interdependência. Parece existir algo para além disso: uma necessidade de cuidados (RONG et al., 2013) para que o sistema continue vivo e saudável (IANSITI e LEVIEN, 2004).

Ainda, o ecossistema de inovação estudado, levando-se em conta a importância do compartilhamento de informações e colaboração em networking (THOMPSON et. al. 2012) fica caracterizado como um ambiente propício ao empreendedorismo 
inovador, que reúne curvas de aprendizagem coletiva, além de intercâmbio de conhecimentos e de práticas produtivas de geração de sinergia entre diversos agentes de inovação, conforme descrito por Spinosa e Krama (2014).

Complementando a abordagem explicitada na análise multivariada de dados relacionadas às incubadoras e parques que constituem a Rede AGROINNCUBA, pode-se propor que as abordagens evolucionistas (Nelson e Winter, 1982) vêm a inovação como um processo dependente da trajetória, por meio do qual o conhecimento e a tecnologia são desenvolvidos a partir da interação entre vários atores e fatores. A estrutura dessa interação afeta a trajetória futura da mudança econômica. Para Andres Felipe Gallego, Coordenador da Media Lab da Universidad Autónoma de Occidente/Colômbia, a incubadora é:

“(...) um espaço experimental onde basicamente o que se busca é que a comunidade se aproxime e, a partir daí, comece a trabalhar no desenvolvimento tecnológico para melhorar seu contexto particular. São espaços onde as pessoas chegam e se conectam com professores, alunos e inovação tecnológica. Temos laboratórios da universidade e principalmente o que procuramos é que, gerem networking para que as pessoas pensem em nós como um espaço de conectividade para buscar novas alternativas. Por exemplo, temos diferentes programas acadêmicos na universidade e o que estamos procurando é que nossos alunos e professores vão para o Media Lab como um mecanismo que se comunica com redes, como a que pertencemos na Rede AGROINNCUBA".

Muito próxima da abordagem evolucionista está a visão que assume a inovação como um sistema. A abordagem dos sistemas de inovação (LUNDVALL, 1992) estuda a influência das instituições externas, definidas de forma ampla, sobre as atividades inovadoras de empresas e outros atores. Ela enfatiza a importância da transferência e da difusão de ideias, experiências, conhecimentos, informações e sinais de vários tipos. De acordo com Celso da Costa Carrer, Coordenador da incubadora da Universidade de São Paulo, UNICETec: 
"Uma incubadora com força empreendedora adequada, também deve promover networking de uma maneira que facilite as possibilidades de mercado para as demandas comerciais. Eu diria que de uma maneira muito especial, a incubadora precisa ser um local ou um tipo de procedimento de acesso aos detalhes do financiamento da inovação, com a ação do acelerador facilitando financiamento direto para as empresas, junto com a incubadora, facilitando o caminho de um empresário para inovar e para enfrentar o mercado". 


\section{CONCLUSÕES}

Diante do levantamento realizado para a verificação da existência de um ecossistema de inovação estabelecido ao redor das incubadoras e parques científicos da rede AGROINNCUBA, pode-se afirmar que este conjunto de atores tem contribuído para a geração de novos negócios inovadores, assim, promovendo o desenvolvimento econômico e social, confirmando-se a hipótese previamente estabelecida.

De modo geral os resultados apontaram que o aspecto mais importante de uma rede, no caso estudado a AGROINNCUBA, são os relacionamentos inter organizacionais, pois a rede prioriza o fortalecimento dessas ligações. Enquanto que, o ecossistema de inovação que permeia a rede, estrutura as funções dos atores envolvidos em um ambiente de negócios.

Tanto a rede como os ecossistemas estabelecidos ao redor das incubadoras, têm cumprido a missão de consolidar a nova sociedade do conhecimento, na qual buscar perpetuar e valorizar a informação e o conhecimento, gerando valor por intermédio da inovação, do empreendedorismo e do desenvolvimento de pesquisas (CASTELLS, 1999).

Os atores dos ecossistemas de inovação da Rede AGROINNCUBA, têm desenvolvido uma cultura direcionada a inovação, dedicando-se a pensar e agir de forma a gerir o conhecimento por meio da tecnologia da informação, da organização do trabalho, da gestão da inovação, gestão de pessoas e de recursos, possibilitando assim ambientes que estimulem a criatividade, a viabilização de talentos, contribuindo para o seu desenvolvimento e fortalecimento (KOROBINSKI, 2001).

A rede AGROINNCUBA pode ser considerada uma comunidade baseada em identidades complementares com interesses comuns para a valorização e disseminação do conhecimento (tanto em termos de incubação de negócios como de mecanismos de transferência). Embora ainda em início de atividade, as atividades até o momento desenvolvidas e analisadas neste estudo, consolidam o objetivo do grupo de criar uma rede dinâmica e participativa onde seus membros possam encontrar: fóruns de discussão, novas oportunidades de negócios científicos e mecanismos para expandir suas redes de contatos de forma organizada (tanto na Europa como na América Latina). 
O estudo obteve uma correlação entre a capacidade de promoção de conhecimento por parte das universidades e o papel decisivo dos parques científicos e das incubadoras para disseminar este conhecimento de forma organizada, a promover e consolidar empresas inovadoras, baseada nos resultados do tratamento das variáveis estudadas. No caso dos ecossistemas ligados ao agronegócio, o estudo espera contribuir para a discussão da importância da inovação no novo paradigma de apoio a estas empresas nascentes pelas incubadoras e parques científicos. Nesse sentido, o pouco tempo de existência da Rede indica que essa questão ainda precisa ser melhor estudada para um resultado em definitivo, sendo uma das limitações para o presente estudo.

Todavia, essas informações podem representar uma contribuição valiosa para o entendimento de ecossistemas de inovação e ajudar a determinar a influência destes para a promoção do compartilhamento de conhecimentos e da difusão de tecnologia para o desenvolvimento territorial, sobretudo ocasionado pelo nascimento de empresas inovadoras e de alto impacto.

Ao final, constata-se ainda, que a utilização de técnicas de análise estatística multivariada mostrou-se adequada para o tratamento dos objetivos propostos e pode auxiliar, de maneira complementar para uma análise qualitativa, de forma eficaz e interessante na consecução do conhecimento nesta área do conhecimento. 


\section{REFERÊNCIAS BIBLIOGRÁFICAS}

ADNER, Ron. Match your innovation strategy to your innovation ecosystem. Harvard business review, v. 84, n. 4, p. 98, 2006.

ADNER, Ron; KAPOOR, Rahul. Value creation in innovation ecosystems: How the structure of technological interdependence affects firm performance in new technology generations. Strategic management journal, v. 31, n. 3, p. 306-333, 2010.

AGROANALYSIS, Equipe. Digitalização do campo. AgroANALYSIS, v. 37, n. 4, p. 33-34, 2017.

AGROPENSA. O Futuro do Desenvolvimento Tecnológico da Agricultura Brasileira. Embrapa Brasília, DF 2014. Disponível em: $<$ https://www.embrapa.br/web/agropensa/ documento-visao $\geq$. Acesso em: 10/08/2018.

AGTECH GARAGE; ESALQ/USP. 1 Censo Agtech Startups Brasil. São Paulo, 2016. Disponível em:<http://www.startagro.agr.br/confira-o-infograficocompleto-do-10-censo-agtech-startups-brasil-em-primeira-mao/>. Acesso em: 06/05/18.

AHUJA, Gautam. Collaboration networks, structural holes, and innovation: A longitudinal study. Administrative science quarterly, v. 45 , n. 3 , p. 425-455, 2000.

ALVIN, C. Rencher. Methods of multivariate analysis. Wiley Interscience, 2002.

ANDERSON JR, Edward G.; PARKER, Geoffrey G. Integration and cospecialization of emerging complementary technologies by startups. Production and Operations Management, v. 22, n. 6, p. 1356-1373, 2013.

ANDRADE, Renato Fonseca de; TORKOMIAN, Ana Lúcia Vitale. Fatores de influência na estruturação de programas de educação empreendedora em instituições de ensino superior. encontro de estudos sobre empreendedorismo e gestão de pequenas empresas, v. 2, p. 299-311, 2001. 
ANPROTEC, Panorama. As incubadoras de empresas no Brasil. 1999.

AUDY, Jorge. A inovação, o desenvolvimento e o papel da Universidade. Estudos Avançados, v. 31, n. 90, p. 75-87, 2017.

AULET, Bill. How to build a successful innovation ecosystem: educate, network, and celebrate. Xconomy. com, v. 14, 2008.

AUTIO, Erkko; KLOFSTEN, Magnus. A comparative study of two European business incubators. Journal of Small Business Management, v. 36, n. 1, p. 30, 1998.

AUTIO, Erkko; THOMAS, L. Innovation ecosystems. The Oxford handbook of innovation management, p. 204-288, 2014.

BARON, Robert; SHANE, Scott. Entrepreneurship: A process perspective. Nelson Education, 2007.

BASOLE, Rahul C. Visualization of interfirm relations in a converging mobile ecosystem. Journal of information Technology, v. 24, n. 2, p. 144-159, 2009.

BATALHA, Mário Otávio. Gestão agroindustrial: GEPAl: grupo de estudos e pesquisas agroindustriais. Editora Atlas SA, vol. 3, 2012.

BATISTA, C. H. Estudo comparativo do desenvolvimento das características comportamentais empreendedoras dos alunos da disciplina de empreendedorismo durante o primeiro semestre letivo de 2004 nos cursos de administração e turismo \& lazer da FURB. 86f. Dissertação (Mestrado em Administração), PPGAd, Universidade Regional de Blumenau. Blumenau. Santa Catarina, SC, Brasil, 2004.

BELLAVER C. IV Workshop do Sincobesp. São Paulo. 2005.

BIZZOTTO, Carlos EN et al. Acompanhamento e orientação de empresas incubadas. SEMINÁRIO NACIONAL DE PARQUES TECNOLÓGICOS E INCUBADORAS DE EMPRESAS, v. 12, p. 1-15, 2002. 
BOUROCHE, Jean-Marie; SAPORTA, Gilbert. Análise de dados. Rio de Janeiro. Zahr Editores, 1982.

BRAMWELL, Allison; WOLFE, David A. Universities and regional economic development: The entrepreneurial University of Waterloo. Research policy, v. 37 , n. 8 , p. $1175-1187,2008$.

BRÜGGEMANN, Henning. Entrepreneurial leadership styles: a comparative study between Startups and mature firms. 2014. Trabalho de Conclusão de Curso. University of Twente.

BURLAMAQUI, Leonardo; PROENÇA, Adriano. Inovação, recursos e comprometimento: em direção a uma teoria estratégica da firma. Revista Brasileira de Inovação, v. 2, n. 1, p. 79-110, 2003.

CARRER, Celso da Costa. Caracterização e diferenciação regional da pecuária de corte no Brasil do fim do século: gênese, modernização e a reestruturação produtiva e mercadológica. 310 p. Tese (Doutorado) FEAGRI/ UNICAMP, Campinas. 2000.

CARRER, Celso da Costa. A educação empreendedora na Universidade de São Paulo: um estudo de caso na Faculdade de Zootecnia e Engenharia de Alimentos. Tese de Livre Docência, FZEA. Universidade de São Paulo. Pirassununga, 2010.

CARRER, Celso da Costa et al. Innovation and entrepreneurship in scientific research. Revista Brasileira de Zootecnia, v. 39, p. 17-25, 2010.

DE PÁDUA CARRIERI, Alexandre et al. Contribuições da análise do discurso para os estudos organizacionais. Revista Economia \& Gestão, v. 6, n. 12, 2008.

CASTELLS, Manuel. A sociedade em rede, vol. 1. São Paulo: Paz e Terra, v. 8, 1999.

CASTRO, Antônio Maria Gomes De. Prospecção de cadeias produtivas e gestão da informação. Transinformação, v. 13, n. 2, p. 55-72, 2001.

DAMIÃO, D.; CATHARINO, M.; ZOUAIN, D. Urban Technology Parks Model as instrument of Public Policies for regional/local development: Technology 
Park of Sao Paulo. In: XXII IASP-World Conference on Science and Technology Parks. 2006.

CHESBROUGH, Henry; KIM, Sohyeong; AGOGINO, Alice. Chez Panisse: Building an open innovation ecosystem. California management review, v. 56, n. 4, p. 144-171, 2014.

CORONA, Leonel. As empresas inovadoras no México. In: 4a Conferência Mundial de Parques. 1997.

DE BRITTO JÚNIOR, Álvaro Francisco; JÚNIOR, Nazir Feres. A utilização da técnica da entrevista em trabalhos científicos. Revista Evidência, v. 7, n. 7, 2012.

DEGENNARO, Ramon P.; DWYER, Gerald P. Expected returns to stock investments by angel investors in groups. European Financial Management, v. 20, n. 4 , p. 739-755, 2014.

DRUCKER, Peter F. Administrando para o futuro. Cengage Learning Editores, 1998.

DUARTE, Rosália. Entrevistas em pesquisas qualitativas. Educar em revista, v. 20, n. 24, p. 213-225, 2004.

DUTIA, Suren G. Agtech: Challenges And opportunities for sustainable growth. Innovations: Technology, Governance, Globalization, v. 9, n. 1-2, p. 161-193, 2014.

ETZKOWITZ, H.; LEYDESDORFF, L. Introduction: Universities in the global knowledge economy. In H. Etzkowitz, \& L. Leydesdorff (Ed.), Universities and the global knowledge economy: a triple helix of university-industry-government relations (pp. 1-8). New York: Continuum. 1997

ETZKOWITZ, H., WEBSTER, A., GEBHARDT, C., \& TERRA, B. R. C. The future of the university and the university of the future: evolution of ivory tower to entrepreneurial paradigm. Research Policy, 2000. 
ETZKOWITZ, H. Hélice tríplice: universidade-indústria-governo: inovação em movimento. Porto Alegre: EDIPUCRS, 2009.

FEFERMAN, I. H. S. PREFÁCIO. Gestão da Inovação. Curitiba: Aymará, 2011. Série UTFinova.

<http://repositorio.utfpr.edu.br/jspui/bitstream/1/2057/1/gestaoinovacao.pdf>. Acesso em: 10/06/2018

FLEURY, A. A. C. Contribuição ao estudo da empresa como sistema. Dissertação (Mestrado) - Escola Politécnica da Universidade de São Paulo. Departamento de Engenharia de Produção, São Paulo, 1974.

FONTES, Margarida. The process of transformation of scientific and technological knowledge into economic value conducted by biotechnology spin-offs. Technovation, v. 25, n. 4, p. 339-347, 2005.

FREEMAN, Chris; SOETE, Luc. A economia da inovação industrial. Editora da UNICAMP, 2008.

FUKUSHIMA, Masayoshi et al. How Startups Explore and Exploit Dynamic Instant Innovation (DII) for New Product Introductions from Experiment to Implementing. 2014.

GITAHY, Yuri. O que é uma startup. Empreendedor Online-Empreendedorismo na Internet e negócios online, 2011.

GODOY, Arilda Schmidt. Pesquisa qualitativa: tipos fundamentais. Revista de Administração de empresas, v. 35, n. 3, p. 20-29, 1995.

GREGOLIN, Maria do Rosario Valencise. A análise do discurso: conceitos e aplicações. ALFA: Revista de Linguística, v. 39, 1995.

GULATI, Ranjay. Alliances and networks. Strategic management journal, v. 19, n. 4, p. 293-317, 1998.

HAGUETTE, T. M. F. Fundamentos teóricos de algumas metodologias qualitativas na sociologia. Haguette TMF. Metodologia qualitativa na sociologia. 1a. ed. Petrópolis: Vozes, p. 24-47, 2001. 
HAIR, Joseph et al. Fundamentos de métodos de pesquisa em administração. Bookman Companhia Ed, 2005.

HOFFMANN, R. Componentes principais e análise fatorial. Piracicaba: ESALQ/USP-DESR, Série Didática, 25p. 76.1992.

IANSITI, Marco; LEVIEN, Roy. Strategy as ecology. Harvard business review, v. 82, n. 3, p. 68-81, 2004.

JACKSON, Deborah J. What is an innovation ecosystem. National Science Foundation, v. 1, 2011.

KAGEYAMA, Angela et al. 0 novo padrão agrícola brasileiro: do complexo rural aos complexos agroindustriais. Campinas: Unicamp, 1987.

KAISER, Henry F. The varimax criterion for analytic rotation in factor analysis. Psychometrika, v. 23, n. 3, p. 187-200, 1958.

KAPOOR, Rahul; LEE, Joon Mahn. Coordinating and competing in ecosystems: How organizational forms shape new technology investments. Strategic management journal, v. 34, n. 3, p. 274-296, 2013.

KHAN, M. W. J.; KHALIQUE, M. Exploring the measurements of organizational performance: review and the small and medium enterprises (SMES) perspective. International Journal of Business Management and Economic Studies, v. 1, n. 1, p. 1-13, 2014.

KIM, W.; MAUBORGNE, R. Value Innovation: The Strategic Logic of High Growth. Harvard Business Review January - February 1997. Boston. 1997.

KIM, W.; MAUBORGNE, R. A Estratégia do Oceano Azul: como criar novos

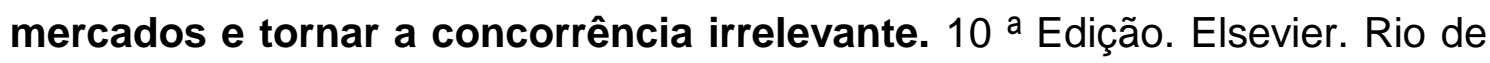
Janeiro. 2005.

KOSLOSKY, Marco Antônio Neiva; DE MOURA SPERONI, Rafael; GAUTHIER, Ostuni. Ecossistemas de inovação-Uma revisão sistemática da literatura. Revista ESPACIOS| Vol. 36 (№ 03) Año 2015, 2015. 
KOROBINSKI, Raquel Rutina. O grande desafio empresarial de hoje: a gestão do conhecimento. Perspectivas em ciência da informação, v. 6, n. 1, 2001.

THOMAS, D. Kuczmarski. What is innovation? The art of welcoming risk. Journal of Consumer Marketing, v. 13, n. 5, p. 7-11, 1996.

LEITE, L. I. F. Empreendedorismo académico e competitividade regional: estudo do impacto do empreendedorismo académico na competitividade de três regiões portuguesas. 168 f. Dissertação (Mestrado) - Curso de Economia Industrial e da Empresa, Universidade do Minho, Braga, 2012.

LEMOS, P. A. B. As universidades de pesquisa e a gestão estratégica do empreendedorismo: uma proposta de metodologia de análise de ecossistemas. Tese apresentada ao Instituto de Geociências como parte dos requisitos para obtenção do título de Doutor em Política Científica e Tecnológica. Universidade Estadual De Campinas; Instituto De Geociências: Programa De Pós-Graduação Em Política Científica E Tecnológica. 2011.

LETEN, Bart et al. IP models to orchestrate innovation ecosystems: IMEC, a public research institute in nano-electronics. California management review, v. 55 , n. 4 , p. 51-64, 2013.

$\mathrm{LI}$, Yan-Ru. The technological roadmap of Cisco's business ecosystem. Technovation, v. 29, n. 5, p. 379-386, 2009.

LODI, J.B. A entrevista: teoria e prática. São Paulo: Pioneira. 1991.

LUNDVALL, Bengt-Ake. National systems of innovation: An analytical framework. London: Pinter, 1992.

MAINGUENEAU, Dominique; CHARAUDEAU, Patrick. Dicionário de análise do discurso. São Paulo: Contexto, 2004.

MANZINI, Eduardo José. A entrevista na pesquisa social. Didática, v. 26, p. 149158, 1990. 
MANZINI, Eduardo José. Considerações sobre a elaboração de roteiro para entrevista semi-estruturada. Colóquios sobre pesquisa em educação especial. Londrina: Eduel, v. 2010, 2003.

MARCONI, Marina de Andrade; LAKATOS, Eva Maria. Fundamentos de metodologia científica. 5. ed.-São Paulo: Atlas, 2003.

RUTHERFORD, Matthew W.; OSWALD, Sharon L. Antecedents of small business performance. New England Journal of Entrepreneurship, v. 3, n. 2, p. 21, 2000.

MOORE, James F. Predators and prey: a new ecology of competition. Harvard business review, v. 71, n. 3, p. 75-86, 1993.

MOORE, James $F$. The death of competition: leadership and strategy in the age of business ecosystems. New York: HarperBusiness, 1996.

DE MORAIS, Edinalva FC. Manual de acompanhamento e auto-avaliação de incubadoras e empresas incubadas. UNB, 1998.

NELSON, Richard R.; SIDNEY, G. Winter. 1982. An evolutionary theory of economic change. 2005.

NUNES, P. Apresentação do Conceito de Startup. Disponível em: http://www.knoow.net/cienceconempr/gestao/startup.htm. Acesso em 04/03/18.

OCDE. Organização para a Cooperação Econômica e Desenvolvimento. Manual de Oslo: proposta de diretrizes para a coleta e interpretação de dados sobre inovação tecnológica. 2a Edição. 1997.

ORLANDI, E. P. Análise de Discurso: Princípios \& Procedimentos. São Paulo: Pontes, 2001.

OUIMET, Paige; ZARUTSKIE, Rebecca. Who works for startups? The relation between firm age, employee age, and growth. Journal of financial Economics, v. 112, n. 3, p. 386-407, 2014.

PASSLEY, Shaun Adam. General Growth Process: Concept to Living Enterprise. 2014. Tese de Doutorado. Benedictine University. 
PLONSKI, G.A.; CARRER, C.C. A inovação tecnológica e a educação para o empreendedorismo In: VILELA, S.; LAJOLO, F.M. (Org.) USP 2034: Planejando o futuro. São Paulo: EDUSP, p.107-135, 2009.

PORTER, M. E. The competitive advantage of nations. New York, NY: Free Press, 1997.

POWELL, Walter W.; KOPUT, Kenneth W.; SMITH-DOERR, Laurel. Interorganizational collaboration and the locus of innovation: Networks of learning in biotechnology. Administrative science quarterly, p. 116-145, 1996.

PwC. Doing Agribusiness in Brazil: PwC Agribusiness Research \& Knowledge Center. 2012. Disponível em www.pwc.com.br/pt/estudos-pesquisas/doingagribusiness.jhtml\&gt. Acesso em 18/09/18.

RANTIN, Eduardo. Tadeu. Impacto das mudanças do apoio do SEBRAE/SP para o ecossistema de inovação: um estudo de caso com incubadoras de empresas do estado de São Paulo. Tese de Mestrado. Universidade de São Paulo. 2016.

RONG, Ke; SHI, Yongjiang; YU, Jiang. Nurturing business ecosystems to deal with industry uncertainties. Industrial management $\&$ data systems, v. 113, n. 3, p. 385-402, 2013.

ROSA, M. V. F. P. C.; ARNOLDI, M. A. G. C. A entrevista na pesquisa qualitativa: mecanismos para a validação dos resultados. Belo Horizonte: Autêntica Editora, 112 p. 2006.

ROTHWELL, Roy et al. Industrial innovation: success, strategy, trends. Chapters, 1995.

SANTANA, Lindaura Maria; HASENCLEVER, Lia; DE MELLO, José Manoel Carvalho. Capacitação tecnológica e competitividade na petroquímica brasileira dos anos 1990: o caso de Camaçari - BA. Revista brasileira de inovação. Rio de Janeiro: FINEP, v.2, n.1, p.147177, 2003. 
SANZ, L. Estrategigrama: un método de análisis y de "benchmarking" de las tipologías de parques científicos y tecnológicos a partir de sus posicionamientos estratégicos. In: ENCUENTRO ESPECIALIZADO PARQUES CIENTÍFICOS Y TECNOLÓGICOS, 3., 2006. Anais... Madrid, 21-22 feb. 2006.

SAWATANI, Y. Innovation patterns. In: IEEE international conference on services computing (SCC 2007). IEEE, p. 427-434. 2007.

SCHLEMM, M. Paradigmas para Inovação. Conduzindo políticas e práticas para o novo estágio. Pesquisa CNPQ. 2014.

SCHUMPETER, Joseph A. Capitalismo, Socialismo e Democracia. Rio de Janeiro: Fundo de Cultura. 1961.

SCHUMPETER, Joseph A. O fenômeno fundamental do desenvolvimento econômico. A teoria do desenvolvimento econômico. Rio de Janeiro: Nova Cultural, 1985.

SCHUMPETER, Joseph A. The economic theory of development. 1912.

SOUZA NETO, José Adeodato de et al. Negociação de tecnologia. Porto Alegre: SEBRAE, 1998.

SPINOSA, L. M.; KRAMA, M. R. Ecossistema de Inovação e Meio Urbano: principais desafios para seus gestores. Research Gate. 2014.

SPOLIDORO, R. Innovation habitats and regional development driven by the triple helix. In: IX Triple Helix International Conference, Silicon Valley. p. 1-23. 2011.

THOMPSON, V.; NASA (In)novation Ecosystem: Taking technology innovation from buzz to reality. In: Aerospace Conference, 2012 IEEE. p. 1-9. 2012.

VICINI, L.; SOUZA, A. M. Análise multivariada da teoria à prática. Santa Maria: UFSM, CCNE, 2005.

VIEIRA, D. P. Facilitadores no processo de inovação tecnológica. 1995. 
YIN, R. K. Estudo de caso: planejamento e métodos. $2^{\mathrm{a}}$ ed. Porto Alegre: Editora Bookman, 2001.

ZAHRA, S. A.; NAMBISAN, S., Entrepreneurship and strategic thinking in business ecosystems, Business Horizons, v. 55, n. 3, p. 219-229, 2012.

ZEDTWITZ, M. Classification and management of incubators: aligning strategic objectives and competitive scope for new business facilitation. International Journal of Entrepreneurship and Innovation Management, v. 3, n. 1/2, 2003.

ZELENY, M.; CORNET, R.; STONER, J.A.F. Management challenges in the 1990s. In: HENNESSY, J.E.; ROBINS, S. Managing Toward the Millennium. New York: Fordham, University Press, p. 3-65, 1991. 


\section{APÊNDICE}

APÊNDICE 1 - Questionário aplicado aos coordenadores das incubadoras

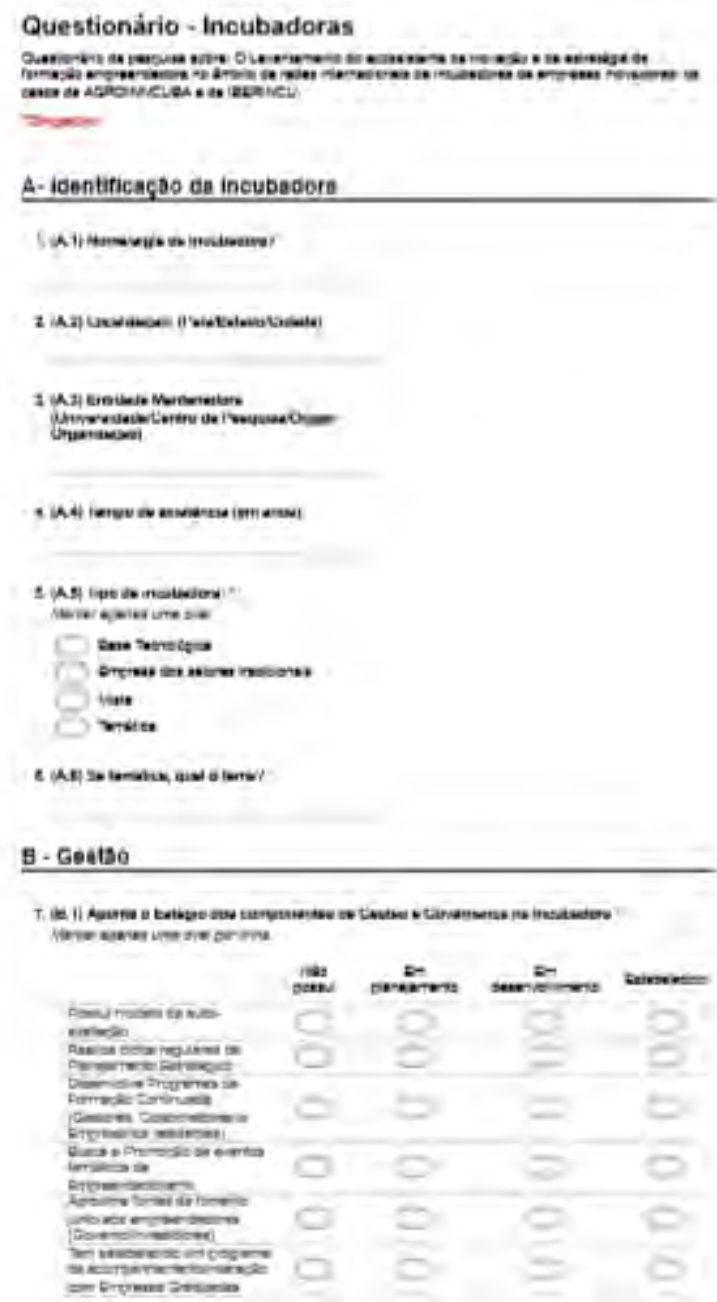




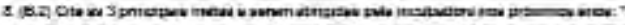

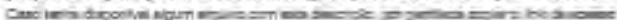

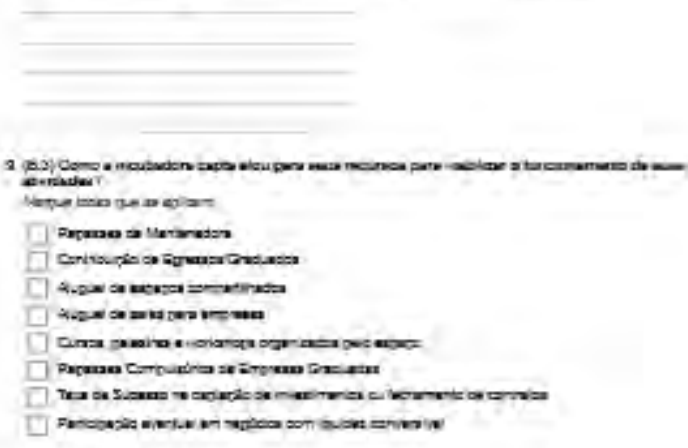

\section{C-Intraestrutura}

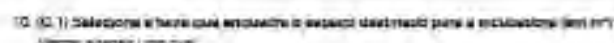

Nimerevereitionsio

- $460 \mathrm{sen}$

ovior $-2.200 \pi$

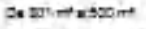

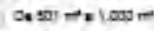

Erera voor

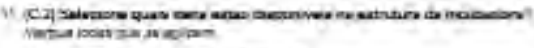

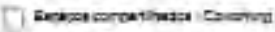

somere

inaterionte

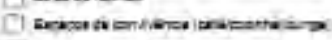

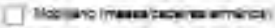

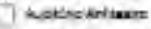

1 indentarate

I Execomats

7 escaut:

| | vexira 


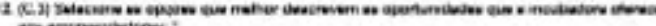

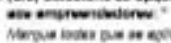

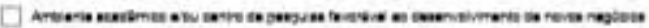

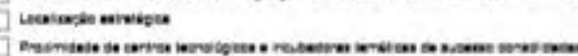

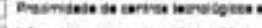

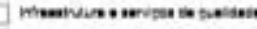

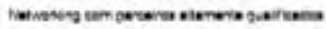

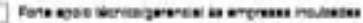

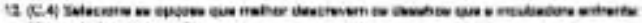

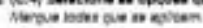

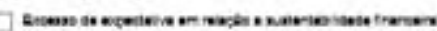

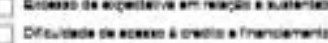

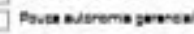

1 neissacke ates nerwiten

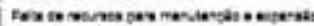

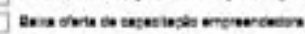

D - Modelo de interaçao com o Eoossistema

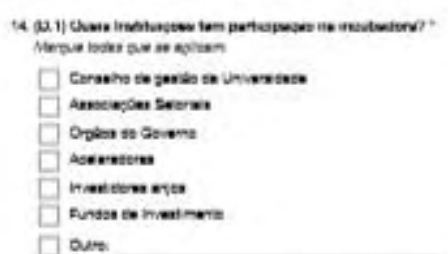

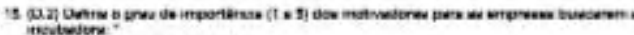

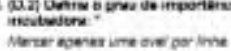

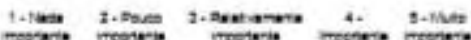

\begin{tabular}{|c|c|c|c|c|c|}
\hline & & & & & \\
\hline 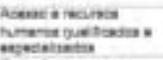 & 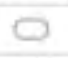 & 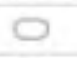 & $\varnothing$ & $\square$ & $\varnothing$ \\
\hline 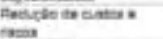 & $\varnothing$ & 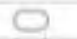 & $\Theta$ & 0 & 0 \\
\hline hatuotivy & $Q$ & 0 & $Q$ & $\square$ & 5 \\
\hline 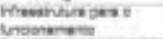 & 0 & $Q$ & $B$ & $\varnothing$ & $\infty$ \\
\hline 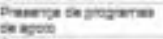 & 0 & 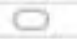 & $\Phi$ & 0 & 0 \\
\hline 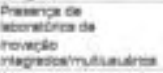 & 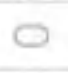 & $\square$ & $\Phi$ & 0 & 0 \\
\hline 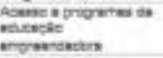 & $\odot$ & 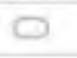 & $\odot$ & $\varnothing$ & 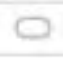 \\
\hline
\end{tabular}




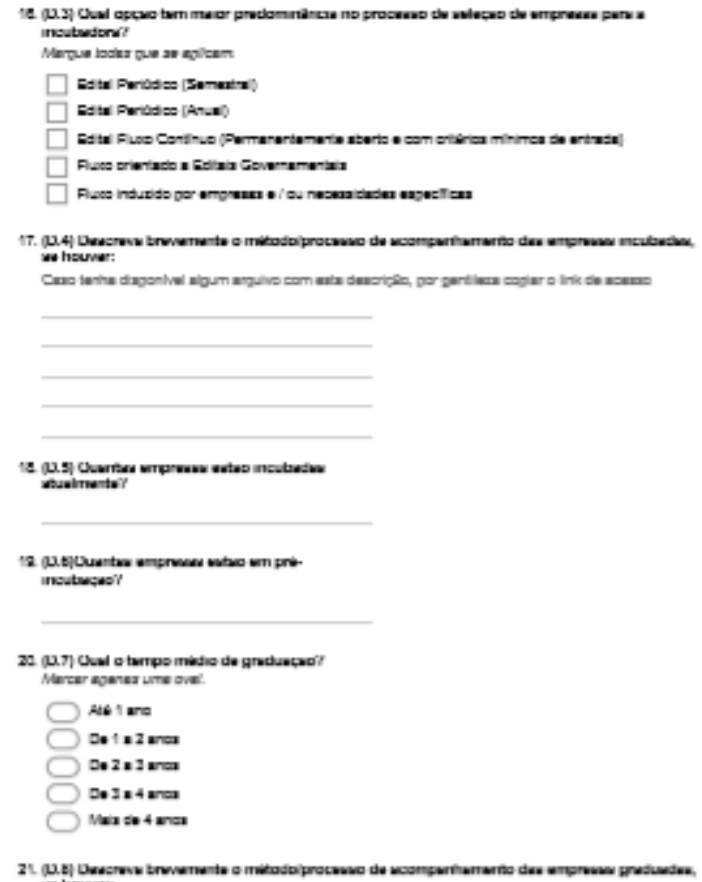

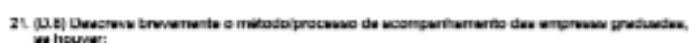

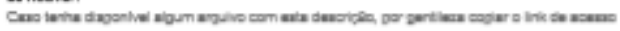

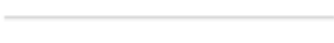

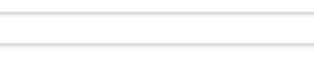

\section{E-Modelo de Formaça Empreendedora}

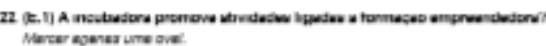

$\square_{m}$ 


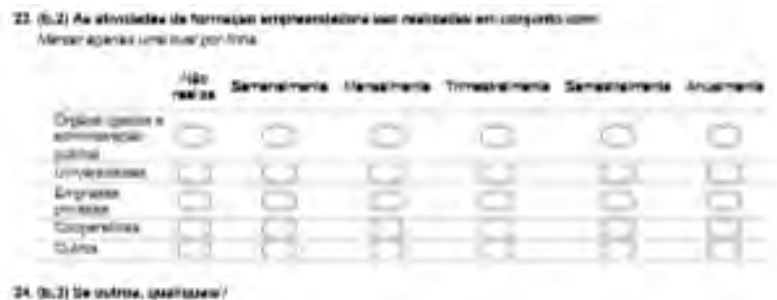

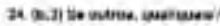

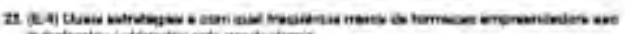

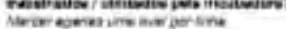
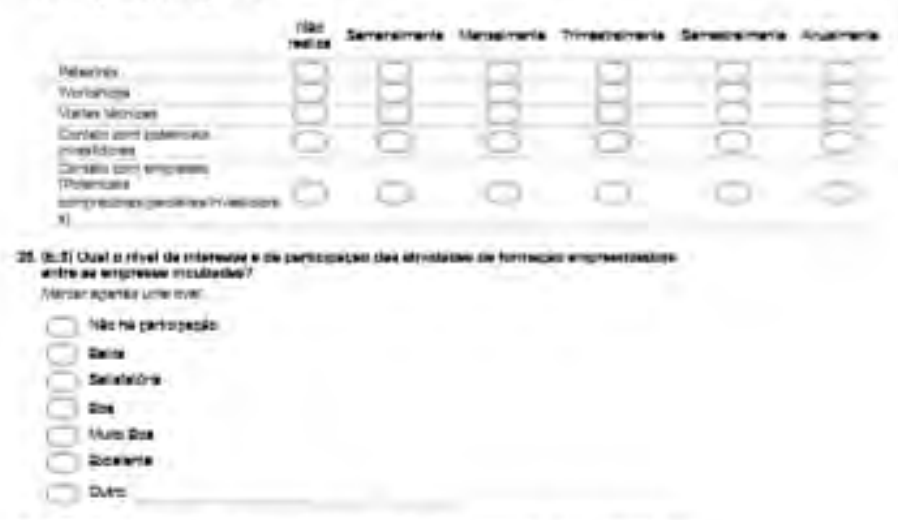

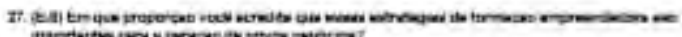

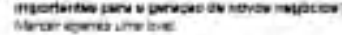

$+2,+, 0,0$

$\bar{\square} \bar{\square} \bar{\square} \bar{G} \bar{G} \bar{G}$

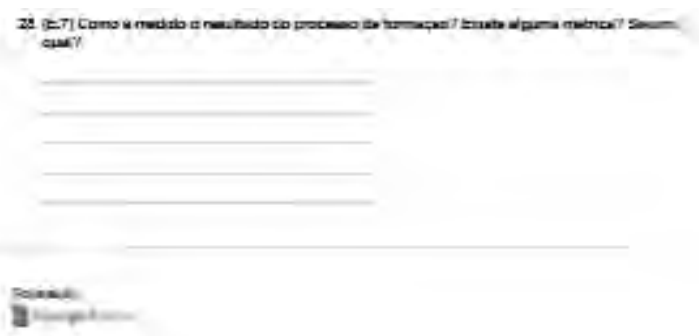




\section{ANEXO}

ANEXO 1 - Status Aprovado do projeto na Plataforma Brasil

\section{- DADOS DA VERSÄO DO PROJETO DE PESQUISA}

Título da Pesquisa: Ecossistemas de empreendedorismo e inovação em redes internacionais de incubação de empresas do agronegócio Pesquisador Responsável: Celso Carrer

Area Temática:

Versão: 1

CAAE: 87688718.2 .0000 .5422

Submetido em: 13/04/2018

Instituição Proponente: UNIVERSIDADE DE SAO PAULO

Situaçăo da Versão do Projeto: Aprovado

Localização atual da Versão do Projeto: Pesquisador Responsável

Patrocinador Principal: Financiamento Próprio 